\title{
Integração para Dados e Aplicações em Biologia Molecular Computacional
}

\author{
MÁrcio Katsumi OIKAWA
}

\author{
DISSERTAÇÃO APRESENTADA AO \\ INSTITUTO DE MATEMÁTICA E ESTATÍSTICA DA \\ UNIVERSIDADE DE SÃO PAULO \\ PARA OBTENÇ,ÃO DO GRAU DE MESTRE EM \\ CIÊNCIA DA COMPUTAÇÃO
}

Área de Concentração: Banco de Dados Orientador: Prof. Dr. João Eduardo Ferreira

\footnotetext{
Projeto com apoio financeiro da Fundação de Amparo à Pesquisa do Estado de São Paulo (FAPESP), sob o número de inscrição 00/10062-3, de 01 de dezembro de 2000.
} 


\section{Integração para Dados e Aplicações em Biologia Molecular Computacional}

Este exemplar corresponde $\check{\mathrm{E}}$ redação final da dissertação devidamente corrigida e defendida por Márcio Katsumi Oikawa e aprovada pela comissão julgadora.

São Paulo, 19 de fevereiro de 2003

Banca examinadora:

Prof. Dr. João Eduardo Ferreira (orientador)

IME-DCC-USP

Prof. Dr. Junior Barrera

IME-DCC-USP

Prof. Dr. Roberto de Alencar Lotufo

FEEC-DCA-Unicamp 
A meus pais, Kumiko e Francisco, meus irmãos e amigos... 


\section{Agradecimentos}

Historicamente, o homem é um ser social. Não somos capazes de viver isoladamente no convívio silencioso de nós mesmos e abdicar da necessidade de compartilhar nossas histórias. Agradecer significa valorizar todos aqueles que participaram de nossa biografia particular e reconhecer sua importância de participante ativo em nossas vidas e na busca de nossos ideais.

Não gostaria de apontar nomes, pois correria o inevitável risco de cometer omissões injustas (resultados do esquecimento espontâneo de minha já não tão boa memória), entretanto há pessoas, cuja participação foi tão presente e acentuada, que pessoalmente não aceitaria que discretamente passassem sem esta menção de agradecimento.

Agradeço a Deus em primeiro lugar, por sua presença sempre almejada e sentida em todos os momentos de minha caminhada e, em particular, durante estes difícieis e gratificantes anos do curso de pós-graduação. Ao professor Dr. João Eduardo Ferreira, por sua receptividade, honestidade, sinceridade e paciência, confiando em minha proposta de trabalho e ajudando nos momentos de indefinição, sabendo ser tolerante e intransigente na condução de meu trabalho, ensinando-me, a cada momento, o caminho para a minha evolução técnica.

Agradeço especialmente à minha família, a meus pais Francisco e Kumiko, e meus irmãos Marcos e Marcelo, por sua presença e participação constante em todos os momentos bons e ruins de minha caminhada, pelos conselhos em momentos de dúvida, pela atenção nos momentos de dor e pela espontânea felicidade em momentos de sucesso. Apesar da distância física que tenho mantido durante os últimos anos, uma das poucas certezas que tenho é a presença e influência positiva em minhas decisões e no traçado de meu caminho pessoal e profissional.

À singular família do laboratório de banco de dados, Bianka, Luciano, Isabel, Tadao, Ariane e Adriano, além dos recentes bolsistas de iniciação científica, pela sustentação e seriedade profissional, além do apoio em momentos de nervosismo, inquietação e frustração, assim como nos momentos de alegria e satisfação.

Aos demais amigos do IME e, em particular, das práticas esportivas de domingo, seguidas de periódicas confraternizações, pela alegria transparente e verdadeira que se repete a cada encontro. Em especial, a meus novos amigos Elcio Yukio Nanba e Alexandre Ryuzo Shinzato, por quem, apesar de pouco tempo de convívio, mantenho a consideração de amigos de longa data, às vezes não tão declarada, embora sentida e, espero, também compartilhada. Devo-lhes muito pelos seus votos de confiança, sua consideração e participação durante os últimos anos.

Aos meus amigos Adriano Lopes Pereira e Ronaldo Cardoso, pela hospitalidade em minha chegada a São Paulo, desculpando-me pelos transtornos que tanto causei e agradecendo pelo sincero sentimento de amizade que cultivamos até o presente momento.

Em especial, também tenho muito a agradecer a minha companheira e amiga Andréia, por sua paciência, compreensão, carinho, cumplicidade e confiança, e ainda por fazer meus dias muito mais felizes. Apesar de sua recente presença, sinto que agradecerei a ela por outras diversas vezes.

Enfim, para todos aqueles que, de forma direta, ou indireta, contribuíram para a concretização deste trabalho; para o Laboratório de Banco de Dados, que gentilmente cedeu suas instalações para a condução de minhas atividades; para o IME e para a USP, que muito bem me acolheu em minha chegada a esta cidade. 


\section{Sumário}

1 Introdução e Caracterização do Problema 9

1.1 Introdução . . . . . . . . . . . . . . . . . . . . . . . . . 9

1.2 Trabalhos Relacionados . . . . . . . . . . . . . . . . . . . . . . 12

1.3 Nossa Abordagem Sobre o Problema . . . . . . . . . . . . . . . . . . . . . 28

1.3.1 Heterogeneidade de Dados . . . . . . . . . . . . . . . . . . . . . . 29

1.3.2 Heterogeneidade de Aplicações . . . . . . . . . . . . . . . . . . . 30

2 Arquitetura de Integração de Dados e Aplicações $\quad 32$

2.1 Nível de Fontes de Dados Brutos . . . . . . . . . . . . . . . . . . . . . . . 32

2.2 Armazenamento e Indexação . . . . . . . . . . . . . . . . . . . . 35

2.3 Integração e Consulta . . . . . . . . . . . . . . . . . . . . . . . . . 37

2.4 Aplicação . . . . . . . . . . . . . . . . . . . . . . . . . . . . 40

2.5 Usuários . . . . . . . . . . . . . . . . . . . . . . . . . . . . . . . . . . . 43

3 Integração de Formatos de Dados 44

3.1 Estrutura . . . . . . . . . . . . . . . . . . . . . . 47

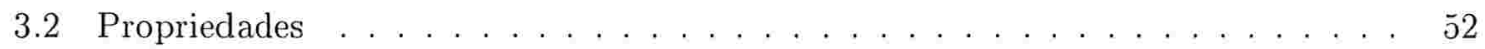

3.3 Relacionamentos e Comunicação . . . . . . . . . . . . . . . . . . 53

3.4 Implementação . . . . . . . . . . . . . . . . . . . . . . . . . . 54

4 Integração de Aplicações de Análise $\quad 56$

4.1 Estrutura . . . . . . . . . . . . . . . . . . . . . . . . .

4.2 Propriedades . . . . . . . . . . . . . . . . . . . . . . 61

4.3 Operadores . . . . . . . . . . . . . . . . . . . . . . . . 62

4.3 .1 Operador de Precedência . . . . . . . . . . . . . . . . . . . 62

4.3.2 Operador de Equivalência de Formatos . . . . . . . . . . . . . . . . . . 63

4.3 .3 Operador de Encadeamento . . . . . . . . . . . . . . . . . . . . . . 63

4.3.4 Operador de Equivalência de Aplicações . . . . . . . . . . . . . . . . . . . 63

4.4 Relacionamentos e Comunicação . . . . . . . . . . . . . . . . . . . . 64

4.4 .1 Aplicações Compatíveis . . . . . . . . . . . . . . . . . . . . . . . . 64

4.4 .2 Aplicações Comparáveis . . . . . . . . . . . . . . . . . . . . . 65

4.4 .3 Aplicações Encadeáveis . . . . . . . . . . . . . . . . . . . . . . . . 67

$\begin{array}{lll}5 & \text { Integração através de Fluxos } & 69\end{array}$

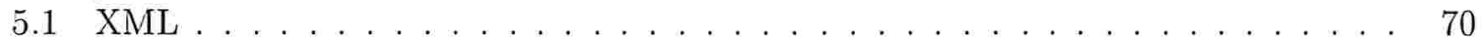

5.2 Fluxos de Execução Genéricos (Gen-Pipe) . . . . . . . . . . . . . . . . 72

5.3 Estudo de Caso . . . . . . . . . . . . . . . . . . . . . . . . . 76

6 Conclusões $\quad 88$

6.1 Resultados. . . . . . . . . . . . . . . . . . . . . . . . . . 88

6.2 Trabalhos Futuros . . . . . . . . . . . . . . . . . . . . . . . 94 


\section{Lista de Figuras}

1 Exemplo de Heterogeneidade Semântica . . . . . . . . . . . . . . . . 15

2 Arquitetura geral do modelo de integração de dados e processos . . . . . . . . . 33

3 Aumento do número de entradas de dados de Genoma (estatísticas do Genbank) 42

4 Meta modelo de dados para informações privadas . . . . . . . . . . . . . 48

5 Meta modelo de dados para Genoma . . . . . . . . . . . . . . . . . . 49

6 Relacionamento entre os subdomínios de sequências de Genoma . . . . . . . . . 54

7 Página inicial do Genbank Mirror USP . . . . . . . . . . . . . . . . . 55

8 Página de consulta de dados do Genbank Mirror USP (sobre o meta modelo de

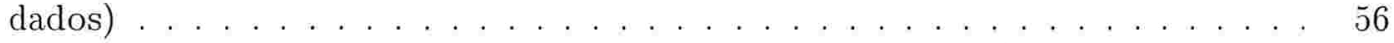

9 Uma das saídas da consulta de dados no Genbank Mirror USP (resultado de busca sobre o meta modelo de dados) . . . . . . . . . . . . . . . . 57

10 Esquema lógico do editor de fluxos . . . . . . . . . . . . . . . . . 74

11 Fluxo genérico-GenPipe . . . . . . . . . . . . . . . . . . 75

12 Fluxo de genotipagem de HIV . . . . . . . . . . . . . . . . . 78

13 Tela de planejamento de execução . . . . . . . . . . . . . . . . . . 80

14 Tela com execução planejada . . . . . . . . . . . . . . . . . . . . 81

15 Edição de parâmetros para cada tarefa do infopipe . . . . . . . . . . . . . 82

16 Integração do infopipe com bancos de dados locais e/ou remotos . . . . . . . . 83

17 Tela de pesquisa de dados de entrada . . . . . . . . . . . . . . . . . . 84

18 Tela de seleção de dados de entrada . . . . . . . . . . . . . . . . . . . 85

19 Acompanhamento do processo de execução . . . . . . . . . . . . . . . . 86

20 Acompanhamento das tarefas intermediárias do infopipe . . . . . . . . . . . . 87 


\section{Resumo}

Um dos grandes desafios atuais na área de Biologia Molecular Computacional é a manipulação de estruturas heterogêneas. Basicamente, podemos dividir este ambiente heterogêneo em dois conjuntos semanticamente distintos: dados e aplicações. A heterogeneidade de dados é representada pela variação estrutural das fontes de dados que armazenam informações biológicas. O crescente volume de dados, sem padronização, tem dificultado cada vez mais a elaboração de estudos conclusivos. A heterogeneidade de aplicações trata as diferenças semânticas e estruturais de um conjunto de implementações algorítmicas (aplicações) utilizadas nas análises dos dados. Nossa pesquisa apresenta uma alternativa para integração de dados e aplicações que usa um ambiente para controle automatizado de um fluxo de execução. Tal controle otimiza o processo computacional de descoberta de conhecimento. Definimos nesse trabalho um metadados para a integração e gerenciamento de dados heterogêneos. Para controlar a heterogeneidade das aplicações definimos um conjunto de operadores para criar um fluxo consecutivo mencionado neste trabalho de gen-pipe. 


\begin{abstract}
One of the actually greatest challenges in the Computational Molecular Biology area is the heterogeneous structures manipulation. Basically we can divide this heterogeneous environment into two semantically distinct sets: data and applications. The data heterogeneity is represented by structural variation of the data source which store biological information. The expanding data volume, without any standardization, has created even more difficulties in the elaboration of conclusive studies. The heterogeneity of applications deals with structural and semantic differences of algorithms implementation sets (applications) utilized in data analysis. Our research presents an alternative for data and application that uses an environment for automated execution flow control. Such control optimizes knowledge discovery computational process. In this research, we have defined a metadata for heterogeneous data integration and management. So as to control the heterogeneity of the applications we have defined an operation sets for creating the consecutive flow called in this research as gen-pipe.
\end{abstract}

palavras-chave: Integração de dados e aplicações, arquitetura de integração, metamodelo de dados de sequência, Biologia Molecular Computacional 


\section{Introdução e Caracterização do Problema}

\subsection{Introdução}

Nos últimos anos, pesquisas envolvendo dados genéticos sofreram um grande impulso. Motivada pelo estudo de novos medicamentos e alternativas de tratamento para diversas doenças, e amparada por investimentos de grandes núcleos de pesquisa, governos e indústrias farmacêuticas, a comunidade científica começou a direcionar trabalhos para esta área. A grande complexidade e multidisciplinaridade deste ambiente, aliada à quantidade e diversidade de novos desafios está originando uma nova área de conhecimento: a Biologia Molecular Computacional.

Com o passar do tempo, muitos investimentos em dinheiro, tempo, conhecimento e material humano foram aplicados, gerando importantes resultados. Hoje, encontramos alguns organismos com sua cadeia de DNA (ácido desoxiribonucleico) decodificada e conhecida, facilitando o entendimento, entre outras coisas, de determinadas reações químicas e do comportamento de certos patógenos diante de específicas condições ambientais. A política e os métodos de planejamento de experimentos também evoluiu, aumentando as chances de sucesso nos resultados finais e evitando desperdício de recursos, tempo e material.

Neste ambiente, o papel do banco de dados é notadamente destacado. Operações de comparação são uma constante na pesquisa laboratorial de experimentos que envolvem sequências de nucleotídeos (que, por conveniência, trataremos neste texto a partir de agora simplesmente por sequências) e no estudo de características macro e microcelulares. Além disso, o volume de dados envolvido é considerável, comprometendo os resultados de manipulações manuais sem o 
devido cuidado. Neste ponto, é de extremo interesse utilizar um sistema gerenciador de banco de dados (SGBD) e módulos auxiliares, capazes de armazenar informação de maneira uniforme e eficiente, além de disponibilizar mecanismos de recuperação e manipulação eficazes.

Nos primeiros experimentos de sequenciamento realizados sobre amostras de variados organismos, os primeiros resultados foram armazenados em arquivos texto, privilegiando informações semânticas de interesse do próprio laboratório ou grupo responsável pela pesquisa. Aliado a isso, vários grupos espalhados pelo mundo começaram a desenvolver suas pesquisas de forma paralela, sem a devida organização em relação ao armazenamento tanto dos dados brutos (iniciais) usados quanto dos resultados finais obtidos.

Esta situação gerou, com o passar dos anos, altos níveis de heterogeneidade de informação entre os dados destes diferentes grupos. Há grande interesse em comparar resultados obtidos por diferentes grupos, não somente para fundamentar resultados locais, mas também para inferir hipóteses, como estudos epidemiológicos a partir de características particulares dos organismos em diferentes regiões geográficas, ou observações semelhantes. Um dos grandes problemas envolvidos é associar dados heterogêneos, tornando-os compatíveis e possibilitando melhor aproveitamento da informação.

Os algoritmos usados para análise e geração de informação possuem, em sua maioria, natureza heurística, levando a um determinado grau de imprecisão no resultado final obtido.

Os métodos heurísticos englobam estratégias, procedimentos e métodos de aproximação por tentativa/erro, sempre na procura da melhor forma de chegar a um determinado fim [1]. As heurísticas foram consideradas durante muito tempo modelos cognitivos por excelência, elas 
se constituem em regras baseadas na experiência e no planeamento, substituindo as anteriores baseadas na procura algorítmica que chega a soluções corretas depois de combinações com todas as soluções possiviveis.

As execuções heurísticas exigem, muitas vezes, menos tempo que as execuções algorítmicas exaustivas, aproximando-se mais da forma como o ser humano raciocina e chega às resoluções dos problemas, e garantem soluções eficientes e aceitáveis, mesmo que não-ótimas em alguns casos. Devido a isto, é possível que um determinado experimento seja realizado por dois grupos diferentes, e seja conduzido a resultados diferentes, mesmo sob condições semelhantes. Neste ponto, surge um nível a mais de heterogeneidade que deve ser considerado, a heterogeneidade de aplicações algorítmicas de análise de sequências, dificultando ainda mais a integração da informação associada.

Do ponto de vista estrutural, podemos tratar a integração das fontes heterogêneas no nível físico tornando suas diferenças transparentes para as aplicações que as utilizam (como veremos no capítulo 2). Este tratamento é realizado na comunicação de fontes de dados semanticamente equivalentes (ou semelhantes), de formatos de armazenamento com estruturação distintos.

Do ponto de vista semântico, a integração deve conservar o conteúdo lógico das fontes heterogêneas, tratando possíveis pontos de ambiguidade ou incosistência de conteúdo. Ambiguidade semântica ocorre em casos onde conceitos diferentes são identificados com mesmo nome, gerando incompatibilidade lógica e estrutural [2]. Este problema normalmente é resultado de inconsistências de projetos ou ambiguidade estrutural. Identificado o fator de heterogeneidade, deve-se projetar um esquema global capaz de tratar, de forma consistente e robusta, todas as 
operações envolvendo a interação entre dados heterogêneos [3].

Neste trabalho, abordaremos um método de integração entre os diferentes níveis de heterogeneidade de dados e aplicações de análise. Nosso objetivo é realizar um estudo aprofundado dos níveis de heterogeneidade entre dados e aplicações, e sugerir, a partir deste, uma solução integradora capaz de tratar de maneira adequada estes níveis, tanto do ponto de vista semântico, como estrutural (maiores detalhes sobre estes critérios serão vistos na seção 1.2).

\subsection{Trabalhos Relacionados}

O tratamento de fontes de dados heterogêneas é um problema bastante frequente na área de Bancos de Dados, principalmente no ambiente corporativo, onde existe a necessidade de trabalhar com sistemas legados. Grande parte das empresas mantém funcionais arquiteturas antigas, por motivos de conservação de informação histórica. Com o passar do tempo, novos sistemas de hardware e software, mais poderosos e com mais recursos foram implantados para a melhoria de desempenho de operações com dados, entretanto muitas dessas plataformas não eram totalmente compatíveis com as anteriores, gerando problemas de comunicação entre ambos os sistemas. Com isso, era necessário trabalhar com bancos de dados heterogêneos, que armazenavam tipos de dados diferentes, geralmente acessados por softwares de gerenciamento distintos e ainda podendo apresentar diferenças de hardware e sistema operacional.

Na década de 80, grande parte dos sistemas se apoiava em aplicações isoladas e centralizadas. Na década de 90, o advento da internet gerou uma grande necessidade de combinação dos dados destes sistemas. O termo bancos de dados federados surgiu para caracterizar técnicas cujo objetivo era possibilitar acesso integrado a um conjunto de bancos de dados distribuídos, 
heterogêneos e autônomos.

Normalmente, os sistemas de informação são avaliados a partir de critérios como autonomia, heterogeneidade, distribuição e flexibilidade. Como estamos interessados diretamente em aspectos de heterogeneidade, priorizaremos este critério, sendo que os demais podem ser estudados com um nível maior de riqueza em $[4,5]$.

A heterogeneidade ocorre de forma natural, pelo fato de que sistemas de desenvolvimento autônomos normalmente utilizam soluções diferentes, por vários motivos, tais como entendimento diferente na modelagem do mesmo conceito de domínio, o ambiente técnico, requisitos específicos de cada aplicação, etc. Isto posto, é possível classificar o níveis de heterogeneidade em três classes: sintática, de modelo de dados e lógica [6].

\section{Heterogeneidade Sintática}

A heterogeneidade sintática pode ser classificada em heterogeneidade técnica e heterogeneidade de interface:

- Heterogeneidade Técnica: engloba diferenças nos aspectos técnicos do sistema, como plataformas de hardware e sistemas operacionais, ou métodos de acesso, como:

- protocolo, como HTTP, SQL, ODBC, CORBA, etc.;

- natureza da conexão (stateless ou state-carrying);

- segurança;

- Heterogeneidade de Interface: existe se diferentes componentes possuem variadas vias de acesso, destacando restrições de métodos: 
- Heterogeneidade de linguagem: linguagens de busca ou restrições de linguagem diferentes. Por exemplo, com ou sem primitivas de busca por negação, sem condições de conjuntos disjuntos, etc;

- Restrições de Consulta: somente um conjunto de consultas é permitido, em determinadas condições. Por exemplo, junções somente entre duas tabelas, etc.;

- Restrições de Amarração: certos valores de atributos devem ser especificados para. validar a consulta.

\section{Heterogeneidade de Modelo de Dados}

- Heterogeneidade de Modelo de Dados: ocorre em casos onde os modelos de dados têm diferentes semânticas para seus conceitos. Por exemplo, o modelo relacional não possui herança, em contraposição ao modelo orientado a objetos;

\section{Heterogeneidade Lógica}

A heterogeneidade lógica trata de aspectos conceituais de modelagem, ou tratamento de relações entre os dados. Podemos subdividir a heterogeneidade lógica em três categorias: heterogeneidade semântica, heterogeneidade de esquema e heterogeneidade estrutural:

- Heterogeneidade Semântica: avalia a semântica de dados e de esquema. Há casos em que esquemas que modelam o mesmo ambiente podem ter diferentes valores semânticos. Os elementos desta modelagem são identificados através de nomes, que induzem o papel de cada item dentro do modelo. Entretanto, o nome não carrega consigo, necessariamente, nenhuma informação semântica agregada, causando incompatibilidade de significado. No 


\begin{tabular}{|c|c|c|c|}
\hline Nome & Lógica & \begin{tabular}{l|l}
$\mathrm{a}$ & $\mathrm{BD}$ \\
\end{tabular} & Biologia \\
\hline José & $\mathrm{x}$ & & \\
\hline Maria & $x$ & $x$ & \\
\hline Antônio & \multirow{2}{*}{$\frac{1}{\text { Nome }}$} & & \\
\hline & & \multicolumn{2}{|c|}{ Disciplina } \\
\hline & José & \multicolumn{2}{|c|}{ Lógica } \\
\hline & Maria & \multicolumn{2}{|c|}{ Lógica } \\
\hline & Maria & \multicolumn{2}{|c|}{ BD } \\
\hline & Antônio & \multicolumn{2}{|c|}{ Biologia } \\
\hline
\end{tabular}

Figura 1: Exemplo de Heterogeneidade Semântica

mundo real, isto pode ser comparado com casos em que a interpretação do mesmo nome não coincide na visão de duas pessoas diferentes.

Dessa forma, há dois casos de conflito semântico que podem ocorrer: nomes iguais que denotam conceitos diferentes (homônimos), ou diferentes nomes que indicam o mesmo conceito (sinônimos). Seguindo o mesmo raciocínio, atributos podem ter o mesmo significado semântico, mas com diferentes unidades de armazenamento.

- Heterogeneidade de Esquema: é a codificação de conceitos em diferentes modelos de dados. No modelo relacional, existem três tipos de conflitos: relacionamento $\leftrightarrow$ nome do atributo, nome do atributo $\leftrightarrow$ valor do atributo e relacionamento $\leftrightarrow$ valor do atributo. Um exemplo para o conflito entre "nome do atributo $\leftrightarrow$ valor do atributo" é mostrado na figura 1 :

Enquanto a primeira tabela modela as disciplinas que um professor ministra como nomes de atributos, a segunda utiliza valores de atributo para o mesmo fim. 
- Heterogeneidade Estrutural: acontece quando os elementos possuem o mesmo significado, são modelados através do mesmo modelo de dados, e são semanticamente homogêneos, mas suas estruturas foram implementadas por diferentes caminhos.

Avaliando, entre outros fatores, o nível de heterogeneidade dos dados, podemos dividir o universo de sistemas de informação em três conjuntos distintos:

- simples: quando a aplicação reside somente em um computador. Esta situação fornece uma ou mais interfaces para seu conteúdo. Os sistemas de informação simples podem ser:

- Sistemas de Banco de Dados que usam algum SGDB para armazenar e gerenciar dados. Em particular, este é baseado em um modelo de dados (que pode ser relacional, hierárquico, objeto-relacional ou orientado a objetos); o dado é estruturado em conformidade com um esquema e manipulado através de uma linguagem de consulta (como SQL);

- Sistemas sem Banco de Dados como sistemas de arquivos, coleções de documentos, coleções de flat files, etc. Estes sistemas normalmente não possuem padronização de formato para os dados e não oferecem uma linguagem de consulta. Sistemas com esta natureza são semi-estruturados se os dados não estão limitados a uma estrutura pré-definida, mas possuem uma organização empírica.

- Sistema de Informação Distribuído: quando o dado está fisicamente distribuído em várias fontes, ligadas por conexões de rede; 
- Sistema de Informação Heterogêneo: é uma coleção de sistemas de informação que se diferencia por suas características sintáticas e lógicas, como plataforma de hardware, modelo de dados ou semântica.

\section{Metadado}

Um outro importante conceito associado a heterogeneidade é o de metadado. Metadado é um dado explicitamente trabalhado na descrição de outros dados ou elementos de sistema responsáveis pela documentação, reutilização de componentes ou interoperabilidade. Sistemas que trabalham com metadados ajudam a desenvolver soluções mais flexíveis e escaláveis.

Podemos distinguir algumas categorias de metadados, a partir de alguns trabalhos com domínios de aplicação mais específicos (como catálogo de dados ambientais e geo processamento $[7])$.

- Metadados técnicos: descrevem informações sobre mecanismos de acesso técnico de componentes, como protocolo, velocidade de conexão, custo de consultas, capacidade de consultas, etc;

- Metadados lógicos: documentam os esquemas e seus relacionamentos. Dicionários de dados e diagramas de classes são bons exemplos de metadados lógicos nos gerenciadores de banco de dados relacional e orientado a objetos, respectivamente;

- Metamodelos: apóiam a interoperabilidade de esquemas em diferentes modelos de dados. É principalmente utilizado em sistemas que trabalham com heterogeneidade de modelos de dados; 
- Metadados semânticos: descrevem a semântica dos conceitos. Em particular, ontologias e thesauri são bons exemplos desta categoria. Todas as descrições específicas de domínio pertencem a esta classe;

- Metadados de qualidade: descrevem propriedades específicas dos sistemas de informação relacionadas à avaliação de qualidade de serviço, como legibilidade, nível de atualização, nível de compreensão, etc.

- Metadados de infraestrutura: ajudam usuários a conseguir informações com algum grau de importância. Isto inclui mecanismos de navegação, como referências anotadas e links de favoritos (em browsers). Note que, neste caso, a relação entre o usuário e a informação é indireta, pois links e referências não possuem dados semânticos, somente amarrações;

- Metadados de usuários: descrevem responsabilidades e preferências de usuários de sistemas de informação. Por exemplo, gerenciamento de perfis de usuário.

\section{Outras Abordagens}

Existem duas abordagens bastante difundidas sobre integração de bancos de dados heterogêneos: o tratamento através de um esquema global de dados e esquema de modelos federados, que segue a idéia que vimos acima $[8,9]$.

No esquema global de dados, esquemas correspondentes a cada banco de dados local são combinados em um único esquema global. Esta solução tende a ser a melhor solução, embora nem sempre sua implementação seja viável. Este esquema tende a ser melhor na medida em que os dados utilizam o mesmo modelo, e todas as operações sobre estes compartilham as mesmas 
restrições. Em modelos globais, problemas de integridade referencial e redundâncias possuem soluções mais simples e métodos de otimização de recursos podem alcançar um nível de sucesso maior. Podemos utilizar o esquema global de dados quando a estrutura semântica dos dados é conservada em seu esquema e, além disso, os esquemas de dados são sintaticamente compatíveis.

No esquema de bases federadas, uma das abordagens é compartilhar pequenos subconjuntos dos esquemas locais com o restante do sistema, abrindo acesso aos modelos através destes $[3,5,4]$.

Em [10], vemos o desenvolvimento de um raciocínio semântico sobre as características dos dados, sua relevância para o sistema e as restrições de integração provocadas pelos níveis de heterogeneidade agregados no domínio de aplicação. A definição do esquema final depende da identificação de pontos de intersecção semântica os subesquemas que estão diretamente ligados. A metodologia para a construção deste esquema é uma variação do método de bases de dados federadas, que nem sempre pode ser totalmente aplicado a um determinado conjunto de dados. Em [2], temos um estudo inicial sobre os principais problemas causados por sistemas de dados distribuídos e as técnicas, métodos e algoritmos mais utilizados para resolvê-los.

A integração de esquemas de dados representa um dos fundamentos básicos para integração de bases de dados e interoperabilidade. Através das duas abordagens acima e de suas variações, é possível definir novos esquemas de dados a partir de outros já existentes. Estes novos esquemas são utilizados para compartilhar toda a informação existente, abstraindo diferenças estruturais e semânticas e definindo o ambiente de execução de consultas, triggers $^{1}$ e funções.

Integrar esquemas é uma tarefa complexa, uma vez que muitas representações de esquemas

\footnotetext{
${ }^{1}$ trigger é uma função previamente definida no sistema gerenciador de banco de dados que automatizam a execução de uma tarefa na ocorrência de alguma operação com dados
} 
não conseguem refletir, em sua plenitude, todas as características semânticas contidas nas bases de dados. Além disso, para alcançar o sucesso nesta tarefa, é imprescindível a interação com designers e administradores, a fim de compreender aspectos semânticos importantes e não violar restrições lógicas muitas vezes implícitas nos modelos. Por este motivo, considera-se que a integração de esquemas não é uma tarefa que pode ser totalmente automatizada [11, 12].

O TSIMMIS é apresentado em $[13,14,15,16]$, um projeto entre a Universidade de Stanford e Centro de Pesquisas da IBM (Almaden) cujo foco é a integração de bases de dados heterogêneas separadas fisicamente, onde a solução passa pela tradução da informação para um modelo de objetos comum, com mecanismos de controle de informação e restrições através das fontes de dados. Atualmente, o TSIMMIS possui alguns serviços disponíveis em seu sítio internet [17], tais como tradução de consultas e informações (wrappers), extração de dados da internet, combinação de informação de várias fontes de dados e rastreamento de bancos de dados sobre a internet.

Há casos em que o problema de integração de dados envolve o tratamento de repositórios de dados, bases de conhecimento, arquivos de sistema e componentes de recuperação de informação. Neste caso, precisamos de componentes de software especiais para recuperar informação das fontes de dados, processá-los, combiná-los e exportá-los para as aplicações requisitantes. Chamamos estes componentes de mediadores $[18,19,20]$. Os mediadores trocam informação entre si e as bases de dados através de um modelo de troca de objetos, com uma especificação de registros, de um protocolo de comunicação e da definição de uma linguagem de consulta derivada do SQL [21]. O TSIMMIS foi utilizado como modelo para avaliação desta arquitetura.

Vários trabalhos posteriores relacionados ao TSIMMIS também discutem temas relacionados 
à heterogeneidade de dados, com ênfase a outros aspectos, tais como visões lógicas [22], bancos de dados federados [23] e integração física de metamodelos [24].

Nos últimos anos, apareceram muitas iniciativas envolvendo trabalhos que utilizam XML como linguagem de estruturação de dados. Em [25], o autor propõe uma arquitetura genérica para integração de dados para a internet, através de uma estrutura de informação definida em XML. Esta estrutura é baseada em regras, através da linguagem XQuery, de definição de consultas em formato XML, e propõe a resolver problemas de integração e heterogeneidade em fontes de dados cuja estrutura varia com grande frequência. A utilização de linguagens baseadas em regras é plausível para fontes de dados de pouco volume, podendo apresentar desempenho insatisfatório em bases com volume considerável. Além disso, uma outra preocupação refere-se a seu conjunto de regras, notadamente complexo e dependente do domínio de aplicação.

Em [26] e [27], discute-se a elaboração e construção de metamodelos de dados e de agentes. Existem situações onde é necessário definir não apenas o modelo de dados, mas também uma metodologia de construção e regras de desenvolvimento da base. Para ambientes onde se faz necessário tratar a heterogeneidade de programas, o raciocínio é similar. Nestes trabalhos, vemos como as regras são utilizadas no domínio de aplicação e como formalizá-las. A exposição do comportamento destas técnicas é ilustrada em exemplos.

Do ponto de vista de aplicações, trataremos sua integração como um fluxo de execução de tarefas. O estudo de fluxos de execução nasceu da automatização de escritório e sistemas de informação gerenciais. A partir daí, o termo começou a agrupar sistemas com caráter mais genérico, cujas propostas variavam de simulações de processos até complexos agentes de automatização de 
tarefas e integração de sistemas legados.

O conceito mais simples para um fluxo de execução seria um conjunto de tarefas integradas que executam sequencialmente. Este processo especifica, entre outras coisas:

- quais tarefas deverão ser realizadas;

- a sequência em que serão executadas;

- por quem serão executadas;

- sob quais restrições serão executadas.

O conceito de fluxo está diretamente relacionado ao de processo. Um processo pode ser definido como um conjunto de tarefas parcialmente ordenadas que conduzem a um objetivo conhecido ou pré-definido. Este processo pode ser subdividido atomicamente em elementos, as tarefas (atividades).

O gerenciamento de um fluxo consiste na execução coordenada de várias atividades, realizadas automaticamente por um sistema de informação, ou manualmente por um operador humano. Durante o estudo e desenvolvimento de um sistema de informação para fluxos, identificamos duas fases claramente distintas:

1. Especificação: consiste na elaboração do plano de execução, verificação das restrições de uso, parametrização e controle de usuários;

2. Implementação ou Execução: consiste na sincronização das tarefas, baseada no plano gerado na especificação. Em um ambiente distribuído, poderíamos ainda incorporar novas 
atividades, como verificação de disponibilidade de hardware e recursos, comunicação de rede, controle de transações, tolerância a falhas, etc.

Métodos de integração de tarefas normalmente são fortemente especializados e específicos de domínio, dificultando a adoção de critérios genéricos para a realização de estudos. Por este motivo, entre a maioria dos autores, não há um consenso sobre atributos consolidados para classificação.

Entretanto, do ponto de vista conceitual, é possível fazer alguns estudos comparativos. Podemos dividir os processos em "orientado à interação humana" e "orientado a sistema". O primeiro classifica processos executados manualmente por agentes humanos. Neste caso, são esperados mecanismos propensos à interação, coordenação e colaboração de operadores não computacionais. Já na segunda categoria, classificamos processos altamente automatizados, que trabalham na integração de componentes heterogêneos, autônomos e distribuídos. Nestes sistemas, a intervenção humana é bastante limitada, e o fluxo é plenamente gerenciado pelo sistema.

Em [28], o autor sugere um outro interessante tipo de classificação baseado em critérios conceituais. Os processos são divididos em "ad hoc", administrativos e de produção.

- Processos ad hoc são aqueles cujas tarefas não podem ser automatizadas, necessitando de intervenção humana. Além disso, a avaliação e tomada de decisão é dinâmica, ocorrendo ao final de cada tarefa, quando é decidido o caminho seguinte do fluxo.

- Processos administrativos descrevem fluxos mais estruturados e organizados, envolvendo tarefas manuais ou simples. Neste caso, é possível determinar a ordem das tarefas antes do 
início da execução do processo. Neste tipo de processo, intervenções humanas não podem ser desprezadas e possuem papel de destaque, embora as tarefas sejam organizadas e de possível previsão.

- Processos de produção representam fluxos mais complexos e altamente automatizados, realizados em ambientes heterogêneos, autônomos ou distribuídos. Estes processos são previsíveis, repetitivos e podem ocorrem sem determinantes intervenções externas ao sistema.

Esta segunda classificação é, na verdade, uma especialização da primeira, onde dividimos o grupo de processos orientados a sistema em dois grupos, onde temos tarefas que podem ser automatizadas, diferenciando-se pelo nível de envolvimento com o ambiente externo ao sistema computacional. A natureza dos processos administrativos nos conduz a fluxos semi-automáticos, onde a tomada de decisão do processo ocorre durante a sua execução, ao final de cada tarefa ou de determinadas tarefas. Dessa forma, o resultado final do fluxo é uma combinação das decisões tomadas durante sua execução. Em contrapartida, os processos de produção nos conduzem a fluxos automáticos, estáticos, onde a decisão do processo ocorre somente após a execução do fluxo. Normalmente, nestes casos, o nível de liberdade para tomada de decisão durante a execução do processo, quando este existe, é extremamente limitado e programável.

Dessa maneira, percebemos que o comportamento do fluxo não mais é do que um reflexo do comportamento de seus elementos (tarefas). Não é fácil definir o papel de uma tarefa dentro de seu fluxo. Esta decisão depende, invariavelmente, do modelo adotado para o domínio e das regras de negócio. Há casos, ainda, em que podemos identificar partições, dentro do mesmo processo, 
que podem ser mais facilmente automatizadas do que outras. É responsabilidade da modelagem avaliar o plano de execução, verificando parâmetros como eficiência e simplicidade.

Portanto, um dos objetivos deste trabalho é generalizar os controles de aplicações semicentralizadas, criando uma estrutura genérica que permita configurar instâncias que atendam a necessidades específicas. Chamamos esta estrutura de infoflow, diferenciando-a do nome clássico de workflow.

Não há um número grande de trabalhos que abordam a integração de dados e aplicações. Quando esta abordagem é feita, muitas vezes, a restrição se faz sobre o ambiente, como em $[29,30,31]$, que se limitam a tratar a integração de fluxos dentro do gerenciador de banco de dados, através de métodos de manipulação de bancos de dados ativos.

Muitos trabalhos apareceram enfatizando aspectos estruturais e protocolos de comunicação e objetos que encapsulam informações. A maioria dos atuais trabalhos nesta linha aponta para mecanismos de integração de sistemas a partir de objetos que se comunicam através de serviços e tornam transparentes detalhes de comunicação de rede.

Um grande avanço na área aconteceu com a definição de novas arquiteturas e protocolos de comunicação, como o CORBA (Common Object Request Broker Architecture) [32]. A idéia principal do CORBA é definir uma arquitetura padrão para a comunicação de aplicações em ambientes heterogêneos. É assumido que as aplicações estão encapsuladas em objetos, e estes fornecem métodos de acesso para outros objetos. Uma das grandes vantagens desta arquitetura é a transparência na manipulação de métodos, cujas chamadas independem da localização física do objeto, abstraindo detalhes de comunicação em rede. 
A grande preocupação de arquiteturas como CORBA é facilitar a implementação de mecanismos de interoperabilidade entre códigos compilados fisicamente separados pela rede. O aspecto de integração, dessa forma, é consequência do tratamento da interoperabilidade definida por tais arquiteturas. Esta abordagem, entretanto, não é suficiente para o nosso caso, em que pretendemos integrar componentes de software que, além das diferenças estruturais, precisam obedecer a determinadas regras de associação.

É interessante perceber que situações desse tipo se manifestam com certa frequência no mundo real, em que temos que buscar meios que, além de abstrair aspectos estruturais, devem obedecer a restrições de parametrização ou determinadas regras de negócios.

Nossa metodologia de integração pode ser utilizada também quando as regras de negócios sejam fortemente ligadas à classificação dos componentes de software em categorias de execução. Estudando tanto as características individuais quanto a importância global de cada componente dentro do cenário semântico, podemos criar regras de encademento e construir fluxos de execução lógicos (gen-pipes), assim como mecanismos de edição.

Um dos ambientes onde esta metodologia pode alcançar bons níveis de sucesso é a pesquisa em Biologia Molecular. Por vários aspectos, já discutidos anteriormente neste trabalho, podemos classificar as aplicações (componentes de software) em categorias de acordo com sua funcionalidade e definir regras de encadeamento. Tais regras são usadas para limitar o universo de possibilidades de encadeamento aos que julgamos válidos e implementar, a partir deste ponto, mecanismos de edição de fluxos de integração.

Um outro desafio é aliar técnicas de integração de aplicações a mecanismos de integração 
de dados. No ambiente de Biologia Molecular, mais que útil, este é um ponto extremamente necessário, uma vez que estamos falando de um universo de aplicações e dados que é altamente dinâmico, desconexo e crescente em termos de volume e complexidade.

Atualmente, é possivel perceber a importância que este tema de pesquisa vem alcançando. A necessidade real por técnicas e mecanismos de integração existe nos mais variados ambientes do mundo real $[33,34,35,36]$. Devido ao caráter específico de cada ambiente, é difícil conseguir metodologias genéricas e abrangentes. Em particular, quando também existem restrições de desempenho, estudos mais detalhados dos cenários e implementações específicas se mostram indispensáveis. Este trabalho aborda uma dessas aplicações, voltada a Biologia Molecular Computacional, uma aplicação de extremo interesse no cenário científico atual e cujo problema de integração é aplicável à nossa alternativa apresentada.

Não são muitos os trabalhos envolvendo o tratamento de heterogeneidade de dados e aplicações analíticas no ambiente de Biologia Computacional, em especial. A heterogeneidade de dados pode ser tratada a partir de estudos semânticos e geração de meta-modelos, quando não possuímos bancos de dados encapsulados em sistemas de gerenciamento diferentes [23]. Com relação à integração de aplicações de análise, temos alguns trabalhos envolvendo grupos de pesquisa em Bioinformática, e que resultaram em softwares de integração de ambiente, como o Artemis [37], GDE [38], GCG [39] ou o pacote Phred/Phrap/Consed [40, 41, 42, 43]. Apesar disso, este tópico de pesquisa é ainda pouco explorado. A capacidade de integrar aplicações de forma eficiente e robusta representa um desafio em Ciência da Computação e uma necessidade para pesquisadores de Biologia Molecular Computacional. A integração transparente do acesso a da- 
dos e da execução de aplicações fornece grande poder de avaliação de métodos e comparação de resultados, muitas vezes desconsiderados quando o trabalho é realizado manualmente.

Buscando uma alternativa, este trabalho mostra que é possível integrar aplicações de análise de dados em uma estrutura de fluxo, através da implementação de fluxos genéricos (gen-pipes). Cada processo é encapsulado em um componente com propriedades e métodos definidos a partir de suas características semânticas. A partir destas definições, classificamos os componentes em categorias de execução e os integramos de acordo com suas relações de encadeamento e compatibilidade, gerando um fluxo unidirecional de execução. Este fluxo pode ser representado por um fluxo de aplicações e configurado dinamicamente através de métodos de edição. O fluxo final obtido espelha total ou parcialmente os experimentos de laboratório, automatizando sua execução. Mais que isto, é possível relacionar este mecanismo de geração de fluxo com sistemas de bancos de dados, integrando-o diretamente ao sistema gerenciador de banco de dados(SGBD).

\subsection{Nossa Abordagem Sobre o Problema}

O problema de heterogeneidade, no ambiente genérico, é altamente complexo. Em função disso, dividiremos este o tratamento deste problema em duas partes distintas: dados e aplicações de análise. Dividindo desta maneira, estaremos isolando estes dois ambientes heterogêneos, na busca de conjuntos com grau de complexidade menor, que facilitem nossos estudos e favoreçam a busca de soluções simples.

Claramente, hoje existe uma forte carência por mecanismos de integração de dados e aplicações de análise. Isto porque esta integração não é tarefa simples, uma vez que envolve o estudo semântico e estrutural de elementos complexos, de natureza multidimensional, com característi- 
cas peculiares e nem sempre claras, que devem ser considerados individualmente ou mantendo relações mútuas. Um outro aspecto a ser considerado é que a Biologia Molecular é uma ciência que infere estudos de natureza altamente dinâmica, abrindo a possibilidade da descoberta de novas fontes de informação, que necessitem de diferentes tipos de dados para estudo e armazenamento, tornando a definição de um modelo universal um desafio ainda mais difícil.

Atualmente, há vários grupos engajados na tentativa de definir metodologias de integração, visando a automatização de tarefas, muitas vezes executadas manualmente, e a melhoria da qualidade e confiabilidade dos resultados obtidos. A demanda por metodologias deste tipo aumenta na medida em que se torna cada vez mais difícil manipular o crescente volume de dados e melhorar sua qualidade final.

Nosso objetivo neste trabalho é estudar com mais detalhes as características heterogêneas de dados e aplicações de análise, propondo uma alternativa de integração para estes ambientes. Também pretende-se formalizar nossa solução e construir um protótipo de um componente de software para integrar dados e aplicações. Este trabalho conta com financiamento da Fundação de Amparo à Pesquisa do Estado de São Paulo (FAPESP), através da concessão de bolsa de mestrado, identificada sob o código 00/10062-3, desde 01 de dezembro de 2000.

\subsubsection{Heterogeneidade de Dados}

$\mathrm{Na}$ área de Bancos de Dados, não é raro encontrar situações onde é necessário trabalhar com bases heterogêneas, geradoras de problemas de integração. Em nosso caso, o principal problema relacionado às bases de dados é o tratamento da heterogeneidade estrutural, sem padrão definido e grande fonte de ambiguidades. 
Ambiguidades representam um importante tópico de pesquisa na área de Bancos de Dados. No mundo real, é frequente encontrar situações onde precisamos manipular fontes de dados com algum grau de ambiguidade, gerados normalmente por inconsistências de projetos ou falhas na modelagem dos dados e dos sistemas.

É inevitável associar Biologia Molecular Computacional ao tratamento de estruturas ambíguas e não-padronizadas. Como dito anteriormente, as sequências e os resultados iniciais obtidos foram armazenados, em sua maioria, a partir de arquivos texto. Cada grupo armazenava as informações mais relevantes de acordo com as próprias necessidades, em formatos que facilitavam a extração local no laboratório. Como muitos grupos trabalhavam em paralelo, muitos resultados foram surgindo simultaneamente. Entretanto, não houve uma preocupação em padronizar os formatos dos arquivos onde a informação era guardada, gerando vários conjuntos de dados com heterogeneidade estrutural e, em alguns casos, semântica.

\subsubsection{Heterogeneidade de Aplicações}

Após a fase de sequenciamento, é necessário realizar estudos específicos sobre um conjunto de sequências, que efetivamente nos fornecerão informações importantes através de operações de comparação, busca de similaridade, formação de árvores filogenéticas, etc. Algumas destas operações, como alinhamento múltiplo de sequências, usam alguns algoritmos heurísticos. A qualidade do resultado final de cada uma das operações acima citadas depende da heurística escolhida para o algoritmo. Cada organismo, ou tecido estudado normalmente possui características particulares, que credenciam uma dada heurística em relação às demais. Mesmo assim, é extremamente desejável comparar os resultados das heurísticas utilizadas. Isto ajuda a consoli- 
dar a qualidade e a confiabilidade dos resultados gerados e permite a elaboração de métricas de comparação entre as heurísticas.

O problema é que as implementações destas heurísticas, a exemplo dos formatos de armazenamento, não obedecem a um padrão de entrada ou saída de dados. Implementações de heurísticas diferentes recebem dados de entrada sob diferentes formatos. A situação é semelhante com relação à saída de dados. Sendo assim, comparar resultados, ou mesmo encadear a execução de heurísticas é uma tarefa trabalhosa, que envolve um esforço adicional de formatação dos resultados e muitas vezes realizada manualmente.

Um caminho para a personalização das heurísticas seria sua reimplementação, direcionando atenção para os formatos de entrada e saída dos dados. Entretanto, julgamos que a reimplementação de heurísticas não é o melhor caminho, uma vez que as heurísticas envolvidas manipulam um considerável número de equações e relações complexas, além de possuírem várias otimizações. Há vários grupos de pesquisadores trabalhando seriamente nesta área e não é nosso objetivo entrar no mérito das heurísticas, propriamente ditas, mas integrá-las sob o mesmo ambiente e fazer o melhor uso possível de seus resultados.

Sendo assim, nosso maior interesse passa a ser a integração dos dados e dos aplicações. A idéia é construir uma arquitetura de integração de dados e processos de análise capaz de tratar, de forma transparente, diferenças estruturais entre os dados e integrar o maior número possível de softwares para tratamento destes. A partir de agora, apresentaremos nossa proposta de arquitetura para a tentar resolver este problema de integração. 


\section{Arquitetura de Integração de Dados e Aplicações}

Nossa estratégia para trabalhar com estes dados heterogêneos é modelar uma arquitetura de integração de fontes de dados e de processos analíticos. Um modelo inicial pode ser visto na figura 2. Note que estamos dividindo nossa arquitetura de software em cinco níveis, sejam eles fontes de dados brutos, armazenamento e indexação, integração e consulta, aplicação e controle de usuários. A partir de agora, discutiremos cada um destes níveis em maiores detalhes, caminhando do nível mais baixo para o mais alto:

\subsection{Nivel de Fontes de Dados Brutos}

Este representa o nível inferior de nossa arquitetura de integração. É neste nível que trabalhamos com as fontes originais de dados, preparando-as para a armazenamento na base operacional. Aqui, estamos preparando o primeiro nível de integração: a integração de dados, que discutiremos com mais detalhes na seção 3 .

Neste nível, trabalhamos com as fontes de dados brutos e com wrappers. Wrappers são componentes de software usados para interligar outros componentes de software. Wrappers podem assumir várias funções, como apresentar uma interface simplificada, encapsular fontes de dados com interface comum, adicionar alguma funcionalidade a uma fonte de dados primitiva, traduzir formatos estruturais ou mesmo expor uma interface interna de uma fonte de dados [44]. Nosso wrapper encapsula uma fonte de dados, trabalhando sobre sua estrutura a fim de tornar sua utilização mais conveniente do que a fonte primitiva.

Em nosso caso, os wrappers são componentes de tradução estrutural. O nosso objetivo é 


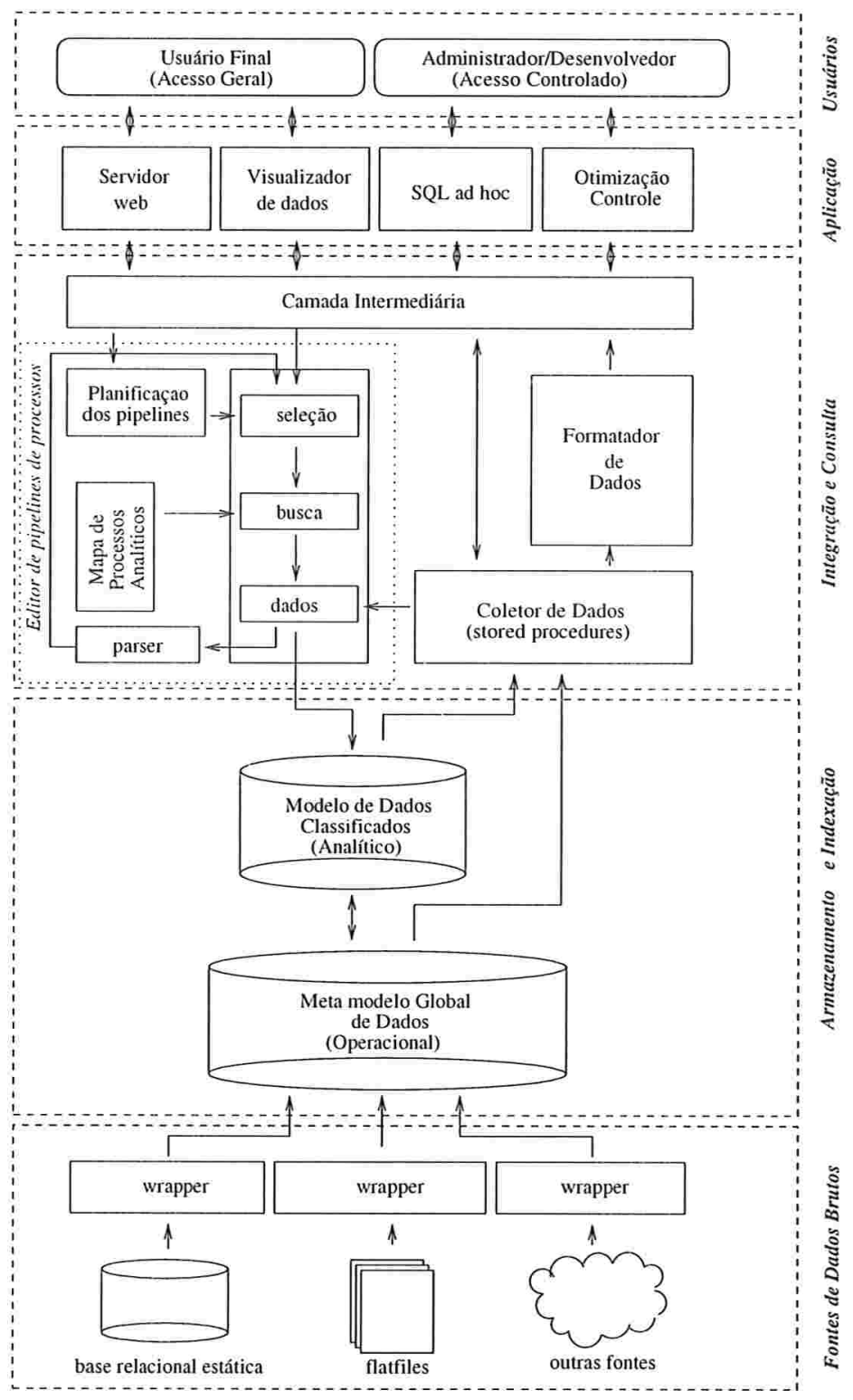

Figura 2: Arquitetura geral do modelo de integração de dados e processos

criar mecanismos de tradução de fontes primitivas de dados para alimentar nosso meta modelo global de dados de Genoma, que discutiremos mais adiante. O objetivo da criação de wrappers é 
fornecer um sistema de tradução independente e flexível das fontes de dados para o meta modelo. Como cada wrapper está intimamente ligado à sua fonte (ver figura 2), temos um mecanismo de integração de formatos com bom nível de escalabilidade, visto que, para acoplar um novo formato de dados ao nosso meta modelo, ou mesmo compensar alterações em formatos já existentes, basta (re)compilar o wrapper a ele diretamente associado.

As fontes de dados representam os dados brutos, de formatos e estruturas variadas, mas que apresentam características semânticas semelhantes, e que desejamos integrar, de alguma forma, para facilitar sua utilização por aplicações em níveis superiores de nossa arquitetura. Por conveniência, decidimos dividi-los em três categorias:

- flat files ${ }^{2}$ - flat files são arquivos que mantêm coleções de dados organizados sob uma estrutura fixa. Em nosso domínio de aplicação, normalmente, estaremos associando flat files a arquivos texto de tamanho variável com estrutura física bem definida, mas sem padronização. Existem alguns flat files considerados mais importantes pelo grau de utilização, informação disponível, ou pelo nível de aceitação na comunidade científica, como o Genbank, o FASTA, [45], o EMBL ${ }^{3}$ [46] e o DDBJ ${ }^{4}[47]$.

- bases relacionais estáticas - são bases de dados, normalmente relacionais, que já possuem esquema e modelo definidos, porém sem as otimizações estruturais do meta modelo de dados do nível de armazenamento. O domínio de aplicação das bases deve ser o mesmo, ou possuir uma considerável intersecção, possibilitando um bom aproveitamento da estru-

\footnotetext{
${ }^{2}$ Flat files são arquivos estruturados, muitas vezes arquivos texto, que armazenam dados de um domínio definido. Apesar de estruturados, os flat files utilizados no domínio de análise de sequência não são padronizados.

${ }^{3}$ European Molecular Biology Laboratory

${ }^{4}$ DNA Data Bank of Japan
} 
tura original. Trabalhando sob o mesmo domínio, espera-se que a distribuição dos dados entre as tabelas e a cardinalidade das relações sejam compatíveis.

- outras fontes - existem outras formas de armazenamento de informação além dos flat files e das bases estáticas, porém menos utilizadas. Podemos ter arquivos texto semi-estruturados ou não estruturados, subconjuntos de registros de dados estruturados, documentos web, artigos, etc. Caso tenhamos uma fonte de dados cujo conteúdo obedeça ao domínio de aplicação de dados que definimos para nossa base, conseguiremos construir um wrapper para carregar sua informação no meta modelo global de dados.

\subsection{Armazenamento e Indexação}

Este é o nível do armazenamento de dados propriamente dito e representa nosso primeiro nível de integração (dados). Neste ponto, trabalhamos com um ambiente de armazenamento e controle dos dados, mantido por um sistema gerenciador de banco de dados (SGBD) responsável, entre outras coisas, por rotinas de segurança de dados, integridade, consistência e controle de transação e usuários.

O armazenamento dos dados ocorre através de duas bases de dados com modelos de dados distintos e escopos diferentes, descritos resumidamente a seguir:

1. Meta Modelo Global de Dados de Genoma - Casos de modelagem de dados envolvendo altos níveis de heterogeneidade estrutural e semântica são difíceis de se tratar através do uso de técnicas de modelagem convencional. A modelagem de dados tradicional abstrai detalhes de implementação do modelo, não levando em consideração situações onde ocorre 
heterogeneidade estrutural. Sendo assim, um modelo de dados, por si somente, não é suficiente para representar adequadamente todos os elementos de um domínio de aplicação bem definido. Para estes casos, definimos um meta modelo de dados.

Um meta modelo é uma estrutura de armazenamento de dados que abstrai ao máximo o conceito semântico dos dados, sendo capaz de representar todos os componentes estruturais de um domínio de aplicação [26]. Como o meta modelo abstrai o conceito dos dados dentro de um domínio conhecido e bem definido, conseguimos construir uma arquitetura quase independente de características físicas, sendo capaz de importar e exportar dados, desde que estes pertençam ao domínio.

Como nosso modelo de dados é abstrato, normalmente enfrentamos problemas de desempenho. Isto ocorre porque, durante o processo de modelagem, somos obrigados a construir nosso meta modelo de modo a aceitar qualquer dado que se encaixe no conjunto de regras do domínio de aplicação, sejam elas estruturais ou semânticas. Pela característica genérica do sistema, as regras de aceitação do domínio não podem ser muito restritivas. Dessa forma, a escolha dos tipos de cada campo dificilmente poderá ser muito otimizada, bem como as regras de integridade ou mesmo a escolha de chaves estrangeiras e algumas relações entre tabelas. Por este motivo, além do meta modelo genérico, faz-se necessário definir métricas e técnicas de indexação, para que o desempenho da base de dados não represente um gargalo para o sistema.

A definição de um meta modelo de dados não se resume apenas à construção das tabelas e das relações entre as mesmas. Neste processo, precisamos definir também as regras de 
relacionamentos, integridade e comunicação de informação, bem como critérios de indexação para tornar o acesso aos dados mais eficiente. Discutiremos melhor estes detalhes na seção 3 ;

2. Modelo de Dados Classificados - Este modelo guarda as características de dados selecionados, resultados de um processo de classificação. O processo de classificação é dependente do experimento realizado pelo pesquisador sobre as informações do meta modelo global, descrito acima, e normalmente envolve a execução de uma sequência de algoritmos de classificação.

Normalmente, a execução destes algoritmos é demorada. O processo de classificação pode envolver a aplicação de funções de mineração, que normalmente são demoradas para grandes volumes de dados e separam os resultados em conjuntos de valores classificados. O objetivo da base analítica é armazenar os dados dentro um formato que consiga conservar as características da classificação realizada. de modo a permitir processos de indexação para otimizar o acesso a informações classificadas.

\subsection{Integração e Consulta}

Este nível representa o foco principal do nosso trabalho. Toda a estrutura do sistema que desenvolvemos se baseia na idéia de integrar dados e processos analíticos. Neste nível, estaremos tratando a integração entre processos, o segundo nível de integração de heterogeneidade de nosso trabalho. Construiremos nosso foco de atenção no processo de sequenciamento, e consequentemente, nos processos utilizados para a obtenção, purificação e tratamento de sequências 
de nucleotideos.

Poderíamos dividir o processo de sequenciamento em várias fases consecutivas, onde os dados obtidos são analisados e, caso possuam relevância no contexto particular do experimento, seus resultados são utilizados para alimentar a fase seguinte, tal como um pipeline. Um pipeline é uma metologia de execução de uma tarefa. Basicamente, a nossa tarefa é dividida em subtarefas (ou fases), onde todas as fases obedecem a uma ordem de execução, como uma linha de montagem, onde o produto gerado em uma fase alimenta a fase imediatamente posterior, até que se conclua a última subtarefa.

Em cada uma dessas fases, aplicamos determinados algoritmos sobre os dados (gerados na fase anterior), e analisamos sua resposta. A maioria dos algoritmos aplicados sobre os dados envolve algum tipo de cruzamento de informação ou comparações. Como estas operações são normalmente lentas, vários autores sugerem a utilização de heurísticas sobre os algoritmos para melhorar o desempenho sem comprometer, entretanto, a qualidade do resultado final. O problema é que a utilização de uma ou outra heurística está fortemente associada com conjunto de dados usado, o grau de confiança no algoritmo escolhido ou mesmo na própria metodologia do experimento.

Além disso, cada uma das implementações de cada um dos algoritmos adota um formato particular para seus dados de entrada e saída, sem a preocupação necessária com a padronização dos dados. Esta situação caracteriza bem a heterogeneidade que gostaríamos de tratar neste trabalho. Temos que fornecer mecanismos de automatização destes algoritmos sobre um dado conjunto de informações, abstraindo seus formatos de entrada e saída. 
É bom salientar, também, que este ambiente heterogêneo é, também, altamente dinâmico. É provável que os processos evoluam e a necessidade por mais informação, além da qualidade dos resultados gerados, siga o mesmo caminho, levando a alterações nos formatos de entrada e/ou saída, de acordo com o lançamento de novas versões de cada implementação. Neste sentido, é também uma preocupação de nossa estrutura não acoplar fortemente os processos a seus formatos de entrada e saída, já prevendo que estes poderão variar de acordo com o tempo, ou mesmo com a requisição do usuário.

Como dito anteriormente, não entraremos no mérito dos algoritmos. Existem grupos especialistas trabalhando na elaboração de heurísticas mais apuradas e técnicas algoritmicas específicas para melhorar os resultados. O nosso foco de interesse é promover mecanismos para integrar o maior número de heurísticas possível dentro de um mesmo ambiente, fornecendo opções de escolha para o pesquisador decidir qual delas é a mais adequada para seu experimento. Este ambiente deve ser o mais transparente possível, para que o pesquisador execute o mínimo possível de tarefas manuais, diminuindo, também, a chance de erros por desatenção humana em algumas das fases de análise.

Em nosso estrutura, idealizamos a construção de um editor de fluxos de processos. Neste editor, estamos utilizando mecanismos de software para tornar dinâmica tanto a construção quanto a execução dos fluxos. A cada um dos processos, temos associado um conjunto de parâmetros de execução, cuja utilização é dependente do experimento em andamento. Como a utilização dos parâmetros é dinâmica, variando de experimento para o outro, temos que refletir este dinamismo para a nossa estrutura de integração. 
Para o sistema, o editor de fluxos executará cinco tarefas:

1. configurar o fluxo - nesta tarefa, é necessário criar uma identificação própria para o fluxo, para que seja possível, no futuro, associar os resultados gerados aos dados de entrada e à sequência de processos utilizados, caso exista a necessidade reconstituir a geração de dados. Nesta fase, tem-se também o cuidado de editar a sequência de processos utilizados, bem como os parâmetros associados a cada um deles;

2. selecionar o fluxo - esta tarefa é responsável pela escolha do fluxo que vai ser executado, entre todos os fluxos cadastrados e configurados no sistema;

3. buscar os dados - nesta fase, define-se quais serão os dados de entrada para o fluxo. A obtenção dos dados ocorre através de rotinas de acesso a bancos de dados do nível de armazenamento e indexação;

4. formatar os dados - cada um dos processos possui um formato de entrada particular. Nesta fase, a estrutura identifica qual o formato de entrada aceito em cada processo e formatar os dados, caso necessário, de maneira que estes obedeçam à estrutura individual de cada um deles;

5. executar os processos - finalmente, a execução dos processos é disparada, utilizando os dados e os parâmetros individuais editados anteriormente.

\subsection{Aplicação}

Representa o nível de interfaceamento entre o usuário e o sistema. É a camada em que temos as aplicações que operam sobre o banco de dados e que realizam chamadas aos processos 
analíticos de dados genéticos. Cada aplicação fará acesso tanto aos dados quanto aos processos através de uma camada intermediária de comunicação localizada um nível imediatamente abaixo (ver figura 2).

As aplicações que farão acesso aos dados foram divididas em quatro categorias:

- Serviços internet: Engloba todas as aplicações de consulta e recuperação de dados, bem como execução e encadeamento de processos de análise. Estas aplicações possuem interface web e, virtualmente, fazem parte do mesmo ambiente, embora possam utilizar diferentes tecnologias e técnicas de implementação, como Java Applets, Servlets, Java Server Pages, $\mathrm{CGI}^{5}$, etc. Estas aplicações são de uso geral e estarão disponíveis para os todos os usuários previamente cadastrados;

- Visualização de dados: Estas aplicações se destinam à visualização de dados e operações dentro do fluxo. Durante a execução do fluxo, muitos resultados intermediários serão gerados e, possivelmente, deverá acontecer algum grau de refinamento entre os processos através da remoção de alguns resultados que não são convenientes ou pelo grau de qualidade, ou mesmo por critérios adotados no próprio experimento. Nestes casos, faz-se necessário uma ferramenta de visualização intermediária dos dados, para poder identificar, de forma amigável, os conjuntos de dados relevantes, separando-os para alimentar as fases posteriores;

- Consultas SQL isoladas: Há casos em que existe a necessidade de realizar uma consulta SQL específica, para testes sobre desempenho da base de dados, satisfazer a uma consulta

\footnotetext{
${ }^{5}$ Common Gateway Interface
} 
com alto grau de personalização ou mesmo executar uma consulta demorada em background. Tais consultas normalmente possuem universo restrito, serão utilizadas poucas vezes e não estão disponíveis através de outras interfaces do sistema. Nestes casos, as consultas serão feitas diretamente sobre a base de dados, através de comandos SQL otimizados;

- Monitoramento e controle da arquitetura: Um problema crítico em relação a bases de dados de Genoma é seu alto grau de crescimento. Nos últimos anos, o volume de dados gerado tem obedecido a uma curva exponencial (ver figura 3). Sendo assim, uma preocupação constante e uma atenção redobrada devem ser destinados ao desempenho da arquitetura diante desta realidade. O objetivo destas aplicações é de monitorar o desempenho do servidor e da base de dados, bem como permitir a realização de testes sobre a base e os processos, a fim de identificar fontes de problemas envolvendo o sistema, monitorá-los e facilitar sua resolução.

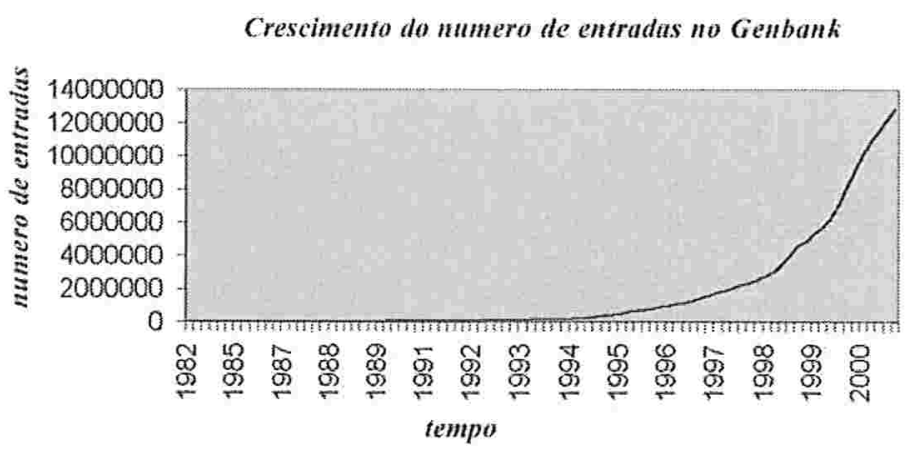

Figura 3: Aumento do número de entradas de dados de Genoma (estatísticas do Genbank) 


\subsection{Usuários}

Este é o nível de controle de usuários do sistema. A utilização da arquitetura está restrita a usuários cadastrados. Serviços de utilização geral como consulta a banco de dados, disponíveis através do Genbank mirror [48], podem ser disponibilizados para um número maior de usuários.

Para maior controle das operações dentro da arquitetura, decidimos fazer uma distinção inicial entre os usuários, a partir do seu escopo. Sendo assim, classificamos os usuários em dois níveis:

1. usuários comuns - representam a grande maioria dos usuários do sistema. Esta categoria é formada por pesquisadores, professores, alunos e estagiários com algum envolvimento em algum dos projetos associados ao grupo de desenvolvimento da arquitetura de integração de dados. Estes usuários têm acesso às aplicações web e às ferramentas de visualização. São responsáveis, também, pela elaboração de consultas SQL ad hoc, mas não possuem permissão explícita para executá-las, podendo fazê-las por intermédio de um usuário administrador;

2. administradores - representam os administradores do sistema. São responsáveis pelo monitoramento dos acessos e da arquitetura. Possuem autorização para executar qualquer um dos componentes da arquitetura e podem ter acesso direto à base de dados. Juntamente com usuários comuns, podem realizar consultas SQL ad hoc e são responsáveis pelos testes de otimização e pela manutenção do sistema. Não representam, necessariamente, o grupo de administração do banco de dados. 


\section{Integração de Formatos de Dados}

Integração de dados é um tema bastante trabalhado na área de Banco de Dados, em função de sua importância, dificuldade e aplicabilidade. Não é difícil encontrar exemplos de situações onde somos obrigados a trabalhar com dados estruturalmente heterogêneos. Há pouco tempo atrás, muitas empresas usavam métodos de modelagem de dados pouco escaláveis, gerenciadores de dados limitados e poucos usuários realizando acessos. Com o advento das redes de computadores, originaram-se novos conceitos, como bases de dados distribuídas e controle de acesso concorrente. Além disso, a mudança de perfil dos usuários, com necessidade de informação mais integrada e realizando requisições simultâneas, acabou influenciando a utilização de sistemas mais avançados. Entretanto, muitas das aplicações existentes ligadas aos sistemas mais antigos, continuaram em funcionamento, gerando um grande problema de tratamento de estruturas legadas, juntamente com informação com algum grau de heterogeneidade.

Se levarmos em consideração, além disso, que o projeto inicial do banco não foi bem trabalhado, ou sofreu alterações ao longo do tempo em função de mudanças nas regras de negócio, a situação pode ser ainda pior. Além da heterogeneidade estrutural, existe a heterogeneidade semântica, cujos conceitos podem ser vistos em detalhes em [10].

O primeiro passo para trabalhar com integração de dados é definir o domínio de aplicação. Em Biologia Molecular Computacional, heterogeneidade de dados é um problema semântico estrutural. Dessa forma, nossa estratégia estará voltada para o tratamento dos dados levando em conta aspectos semânticos, mas com ênfase à parte estrutural.

Estamos interessados em construir um modelo de dados semanticamente genérico dentro de 
nosso domínio de aplicação, ou seja, um esquema de tabelas modelado segundo os conceitos de nosso domínio e, por isso, capaz de importar e exportar informação de quaisquer outras fontes de dados, desde que estas também estejam inseridas no mesmo domínio.

Podemos definir uma fonte de dados primitivos como uma estrutura de armazenamento de informação persistente. Esta estrutura possui um formato fixo e definido, sendo representado por flat files, arquivos estruturados ou semi-estruturados. Usamos também a definição de uma arquitetura da base operacional, que representa o esquema de tabelas físicas resultado da análise e modelagem de requisitos de um domínio. Assumimos que este esquema é gerenciado por um SGBD.

Para garantir a correção de nossa estrutura, temos que encontrar uma função bijetora $\delta_{i}$ : $W_{i} \rightarrow X$, onde $W$ é o conjunto de todos as fontes de dados primitivos de sequência, $W_{i}$ uma instância de $W$ (conjunto das fontes de dados de um tipo $W_{i}$ específico) e $X$ a arquitetura da base operacional. A função $\delta_{i}$ importa a informação de $W_{i}$ para $X$, além disso, $\forall \delta_{i}, \exists \omega_{i}: X \rightarrow W_{i}$, inversa a $\delta_{i}$.

Ou seja, nossa arquitetura parte da hipótese de que é possível importar qualquer flat file $W_{i}$ para a estrutura de banco de dados operacional, através de $\delta_{i}$ e, da mesma forma, exportá-lo para qualquer formato $W_{j}$ através de $\omega_{j}$.

Nossa base de dados, neste momento, trabalha sob uma única arquitetura, que chamaremos base de dados operacional. Se conseguirmos garantir a existência de $\delta_{i}$ e, consequentemente, de $\omega_{i}$, resolveremos o problema de heterogeneidade de formatos de dados, uma vez que, a partir de agora, toda a nossa arquitetura funcionará levando em conta a base operacional, funcionando 
de forma independente dos flat files. Não correremos riscos de perder informação, uma vez que toda a estrutura semântica dos dados de cada flat file está incorporada à nova arquitetura.

É bom ressaltar que, nem sempre é possível exportar de um formato $W_{i}$ para outro $W_{j} \mid j \neq i$ com total sucesso. Em função das diferenças estruturais, é possível encontrar situações onde o processo de conversão não é simples. Consideremos um exemplo para tornar o problema mais claro. Suponha dois formatos de dados, $x$ e $y \mid x, y \in W$, sendo que queremos mapear $x$ para $y$. No formato $x$, temos um campo, no conceito publicação, endereço (char (100)) e no formato $y$ temos uma tabela enderę̧o, com campos especificados (rua, CEP, cidade, país, etc.). O formato $x$ aceita endereços sem CEP, o que não ocorre com o formato $y$. Sendo assim, não conseguiremos converter totalmente um registro no formato $x$ para o formato $y$, em função desta restrição. Este problema não pode ser totalmente resolvido, mas a conversão é possível, se atribuirmos à função $\delta_{x}: x \rightarrow W$ um grau de tolerância a restrições como esta. Este problema é tratado internamente no integrador, considerando a tolerância do meta-modelo de dados, que é mais genérico. Note que, em nosso meta-modelo, abstraimos totalmente o conceito de endereço, não prendendo o formato a detalhes específicos, tornando possível utilizar ambos os formatos dentro de uma arquitetura de integração. Dessa forma, mudanças de formato passam a ser transparentes ao pesquisador, prevenindo intervenções manuais no tratamento dos dados e automatizando procedimentos de conversão.

Dessa forma, definiremos nossa estrutura baseada em conceitos inerentes à Biologia Molecular, definindo estrutura, propriedades e operadores adequados para tratar nosso modelo final. 


\section{$3.1 \quad$ Estrutura}

Dados biológicos devem ser tratados como objetos complexos. Objetos complexos são objetos que possuem, ou mantém, entre si, relações de características complexas, como agregações, relações recursivas, hierarquias, etc. O modelo relacional clássico não é adequado para modelagem de estruturas com tais características, pois não consegue conservar, de forma eficiente e completa, a natureza destas relações $[49,50]$. Para contornar este problema, precisamos utilizar técnicas mais abrangentes, como modelagem de dados orientada a objetos, que é capaz de tratar relações cujas propriedades não podem ser representadas totalmente através da modelagem relacional.

Os dados, armazenados sob diferentes formatos estruturais, do primeiro nível do sistema de integração são imediatamente tratados no nível acima, através da bases de dados operacional. A idéia principal é limitar o modelo de dados a um domínio de aplicação específico (dados de sequências genéticas) e, baseado em regras e propriedades deste domínio, definir um modelo genérico, capaz de refletir o conteúdo semântico das bases de dados já existentes.

Com isso, definimos seis subdomínios, sejam eles:

- usuários;

- sequência;

- referências bibliográficas;

- características;

- experimentos; 


\section{Meta Modelo de Dados Privados de Genoma}

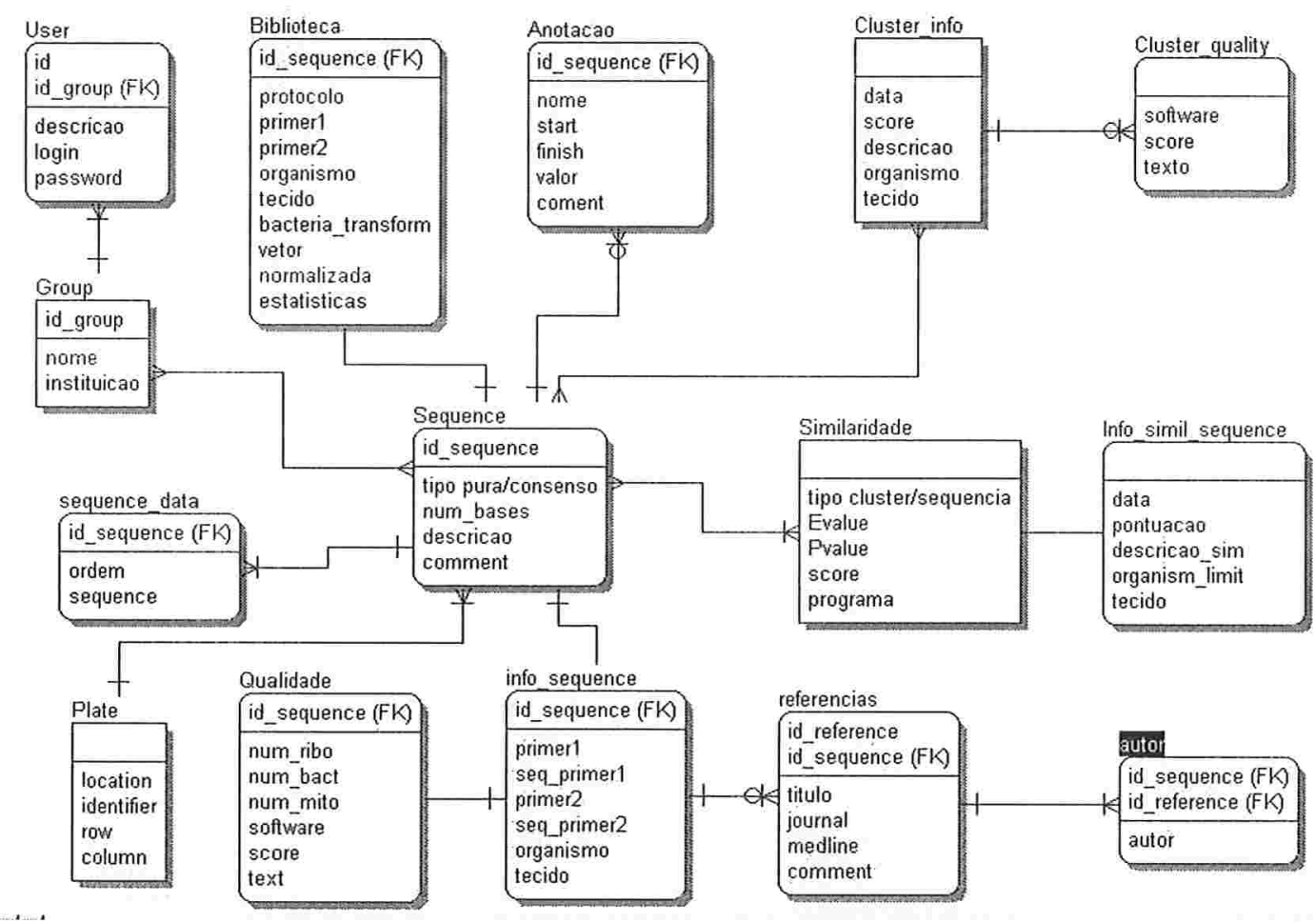

Figura 4: Meta modelo de dados para informações privadas

- dados adicionais

Definição 1 : Usuário é o subdomínio caracterizado por uma tupla (uid, nome, grupo), onde uid é uma identificação única pertencente a cada usuário, nome representa o nome de usuário cadastrado no sistema e grupo indica o grupo de trabalho ao qual cada usuário está associado.

Definição 2 : Sequência é o subdomínio caracterizado por uma tupla (sid, seq), onde sid é uma 


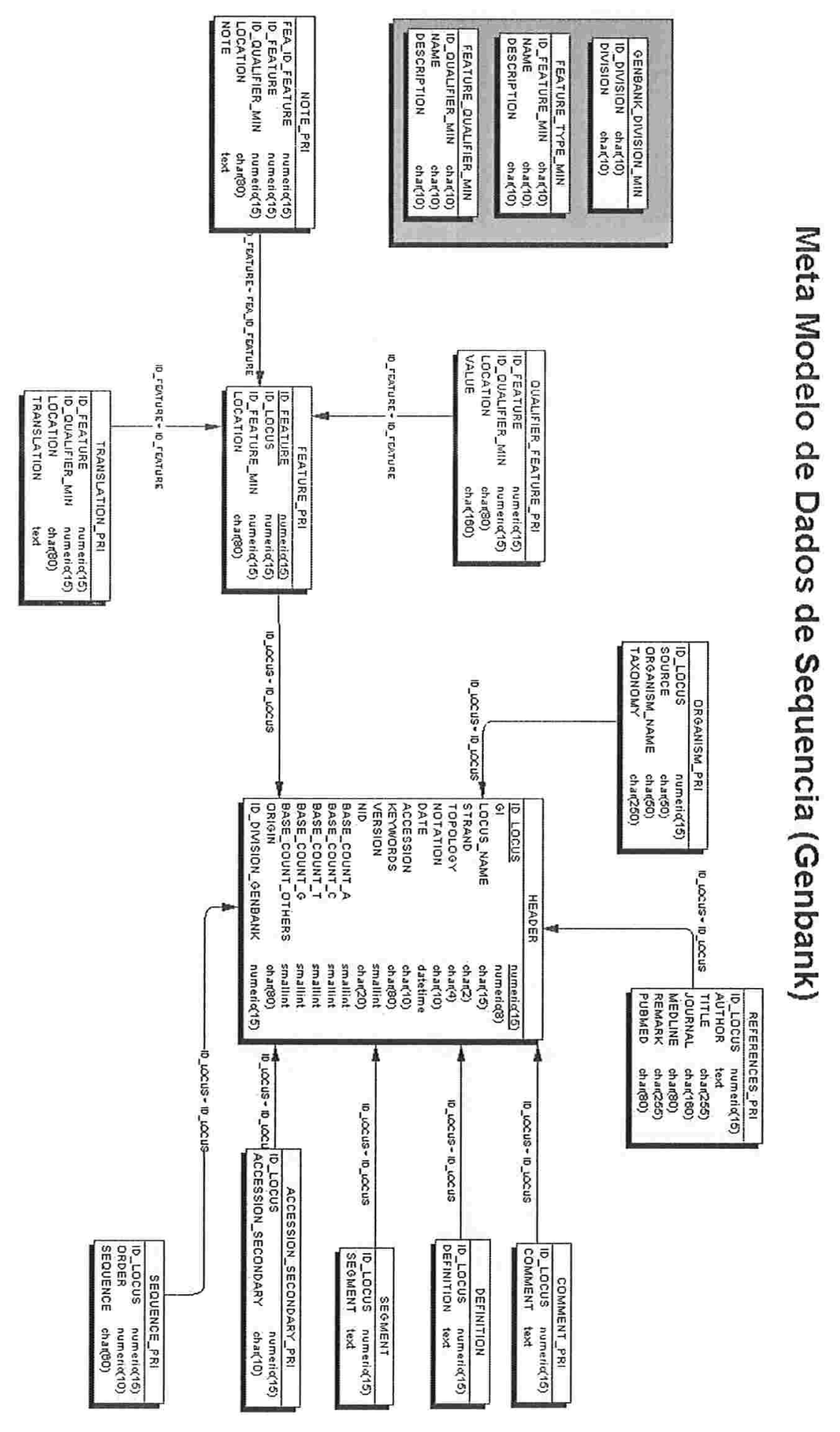

Figura 5: Meta modeld9le dados para Genoma 
chave de identificação única pertencente a cada sequência e seq é a sequência de nucleotídeos propriamente dita, uma cadeia de caracteres formada por uma sequência de letras do conjunto $\{a, c, t, g, n\}$, onde a representa adenina, $c$ citosina, $t$ timina, $g$ guanina e $n$ representa uma base não identificada, podendo ser uma das quatro anteriores. Bases com caracter $n$ podem representar posições com baixa qualidade de sequenciamento.

Definição 3 : Organismo é o subdomínio caracterizado por uma tupla (oid, oname, taxonomy), onde oid é uma chave de identificação única pertencente a cada organismo, oname armazena o nome do organismo fonte do qual foi extraída a sequência e taxonomy guarda a identidade taxonômica do organismo estudado.

Definição 4 : Referência (Bibliográfica) é o subdominio caracterizado por uma tupla (rid, autor, journal, medline, remark, pubmed), onde rid é uma chave de identificação única pertencente a cada referência cadastrada, autor representa uma lista com os autores da publicação, journal representa o instrumento de publicação (revistas, anais, relatórios, etc), medline representa um resumo do trabalho publicado, remark representa comentários adicionais referentes à publicação e pubmed representa uma lista com chaves de busca em outros bancos de publicações.

Definição 5: Anotação é o subdominio caracterizado por uma tupla (cid, token, valor), onde cid é uma chave de identificação única pertencente a cada característica encontrada, (anotação)token representa o nome da característica encontrada, e valor representa o valor associado à mesma.

Definição 6 : Experimento é o subdomínio caracterizado por uma tupla (eid, usuario, seq, class), 
onde eid é uma chave de identificação única pertencente a cada experimento, usuário representa uma lista com os usuários que possuem acesso aos dados do experimento realizado, seq representa o conjunto de sequências envolvidas no experimento e class representa o critério de classificação utilizado para a realização do experimento.

Definição 7 : Dado adicional é o subdomínio caracterizado por uma tupla (did, carac), onde did é uma chave de identificação associada a cada conjunto de dados adicionais cadastrados, e carac representa uma lista com as caracteristicas adicionais encontradas para a informação. Esta classe de objetos representa informações de importância secundária, mas relevante dentro do modelo.

Os subdomínios se relacionam de acordo com suas propriedades semânticas e podem ser vistos na figura 6. Com base nestes subdomínios, definiremos propriedades e regras de comunicação.

Uma das relações que temos que tratar é o controle de acesso da informação. Podemos dividir os dados em dois conjuntos: dados privados e públicos. Os dados são, inicialmente, privados, resultados de pesquisa, sequenciamento, comparações e experimentos. Durante este período, os dados pertencem exclusivamente ao próprio pesquisador ou seu grupo (a depender do critério adotado para o andamento e avaliação da pesquisa). Uma vez que os experimentos são realizados com sucesso, produzindo resultados interessantes, estes são publicados, reconhecendo a relevância do trabalho. A partir deste momento, quando é dada a devida menção ao grupo de pesquisa envolvido, os dados se tornam públicos, originando uma nova categoria de dados, resultados consolidados.

É de extremo interesse que dados públicos e privados sejam tratados de forma diferenciada, 
uma vez que o controle de acesso requer requisitos particulares. Para informação pública, não é necessário gerenciar controle de acesso de usuários. Para informação privada, entretanto, é necessário criar mecanismos de controle de acesso robustos e dinâmicos. O necessidade de mecanismo dinâmico se justifica pela possibilidade de pesquisas conjuntas, quando o proprietário do dado modifica seus atributos de permissão em favor de outros pesquisadores, ou grupos.

Para facilitar a definição do modelo, dividimos a informação em dois modelos de dados. O modelo de dados privados, mostrado na figura 4, é responsável pela representação dos subdomínios de sequência, usuários e experimentos. Já o modelo de dados públicos, mostrado na figura 5 é responsável pela representação dos domínios de sequência, referências bibliográficas, características e dados adicionais. Note que a interseç̧ão entre os dois modelos é representada pelo sub domínio de sequências, que representa o elo de ligação entre as duas categorias de dados.

Os modelos criados são semi independentes, facilitando a elaboração de regras para ambos, que pode ser feita em paralelo. Apesar de semi independentes, é necessário definir mecanismos de comunicação entre eles. Dessa forma, aproveitaremos o fato do sub domínio de sequências ser comum a ambos, definindo os mecanismos de comunicação em função dele. A especificação do modelo de dados privados ainda está em andamento, uma vez que é necessário a participação de usuários para a definição das regras e categorias de controle de acesso necessárias. A especificação do modelo de dados públicos está finalizada e foi testada com a inclusão de uma base de dados pública considerada referência na comunidade científica, o Genbank.

\subsection{Propriedades}

Cada subdomínio é uma classe de elementos, que possui existência própria, sendo capaz de se 
comunicar com outros domínios através de regras de associação, baseadas em suas características semânticas e estruturas particulares. Com exceção de experimentos, os demais sub domínios possuem vida própria, ou seja, existem logicamente de forma independente. Experimentos são formados por relacionamentos entre usuários e sequências, mas devido ao seu grau de importância dentro do modelo e à presença de atributos próprios, tais como o critério de classificação, pode ser considerado como uma pseudo classe de elementos, que apresenta características semânticas e estruturais relevantes, justificando seu tratamento através de uma classe de elementos.

\subsection{Relacionamentos e Comunicação}

Os subdomínios representam entidades dentro do nosso modelo. A relação entre eles coincide com a cardinalidade de suas relações, explícita na figura 6. Círculos pretos indicam mapeamento para várias instâncias. Por exemplo, no relacionamento entre sequências e referências bibliográficas, temos uma relação 1-para-n, ou seja uma sequência pode estar associada a várias referências, mas uma referência pode estar associada somente a uma sequência. Da mesma forma, experimentos e usuários possuem uma relação n-para-m, ou seja, um usuário pode estar associado a vários experimentos e, em contrapartida, um experimento pode ser compartilhado por vários usuários.

Relacionamentos e cardinalidades são conceitos básicos de modelagem relacional. Não faz parte do escopo deste trabalho discutir detalhes de modelagem, então não entraremos em detalhes, mas caso haja interesse em maiores informações, [51, 52] são boas referências. 


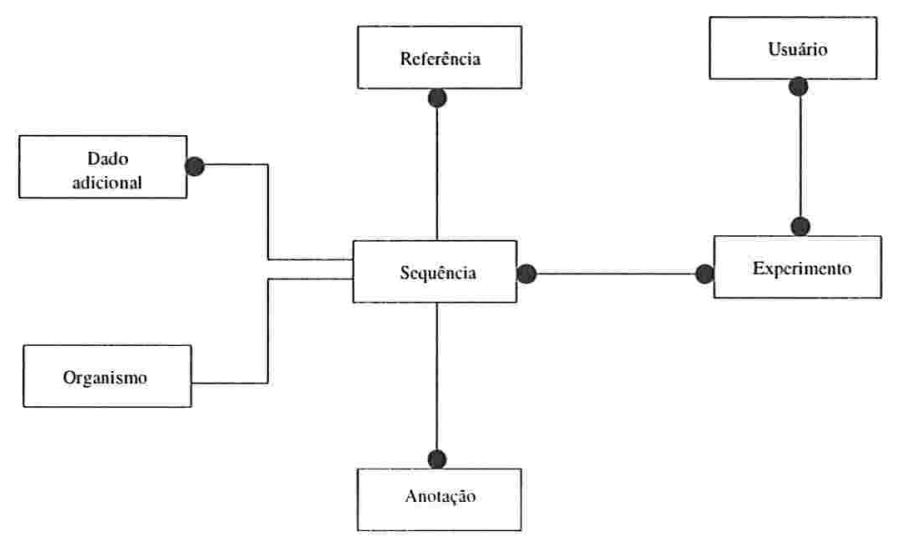

Figura 6: Relacionamento entre os subdomínios de sequências de Genoma

\subsection{Implementação}

Brevemente, o Núcleo de Bioinformática da Universidade de São Paulo (BIOINFO-USP) deverá deixar disponível um sítio internet para consulta de dados genéticos. A proposta deste sítio é servir como um caminho alternativo para busca de dados e personalização de consultas sobre dados de Genoma advindos de várias bases de dados públicas espalhadas pelo planeta. Com a criação deste sítio, a comunidade científica da USP poderá ter acesso mais rápido e sem restrições a todos os dados públicos disponíveis pelo NCBI, EMBL, DDBJ e outras bases.

A implementação do banco de dados usado para armazenar todas as informações foi feita utilizando o metamodelo de dados públicos, cuja arquitetura pode ser vista na figura 5 .

A figura 7 mostra a página inicial do serviço de consulta de dados do Genbank Mirror USP. A figura 8 ilustra a página de consulta propriamente dita, onde existem várias opções de chave de busca para os dados armazenados no meta modelo. O usuário, uma vez escolhida a chave de busca e submetida a consulta, tem a possibilidade de escolher o formato de visualização da 


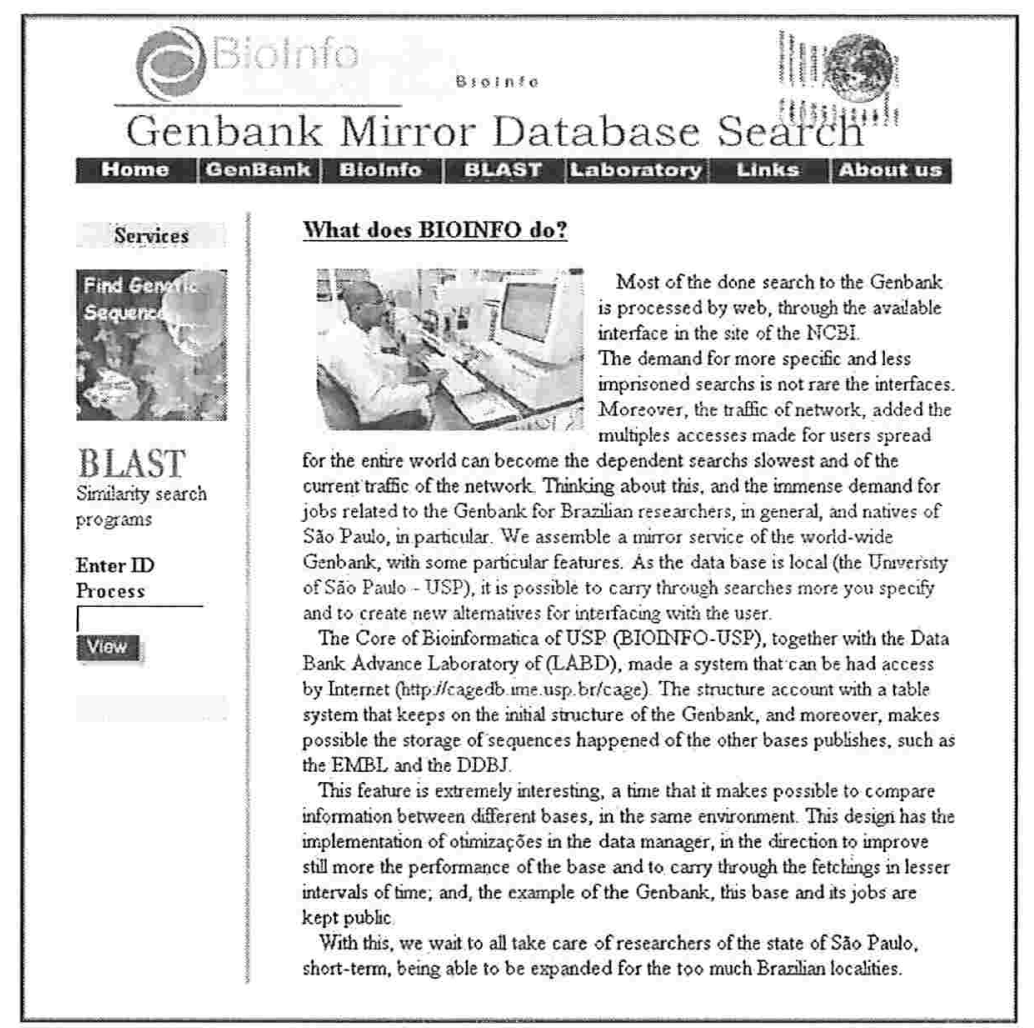

Figura 7: Página inicial do Genbank Mirror USP

resposta. Na figura 9 ilustramos a saída no formato Genbank flat file.

Note que, uma vez que os dados estão armazenados no meta modelo, é possível escrever rotinas de conversão estrutural para qualquer formato semanticamente coberto pelo domínio de aplicação que escolhemos. Momentaneamente, a título de teste, o site cobre apenas os formatos FASTA e Genbank flat file, entretanto a nossa proposta é possibilitar rotinas de exportação para outros formatos de dados, como Genbank, EMBL, ASN, XML, etc. 


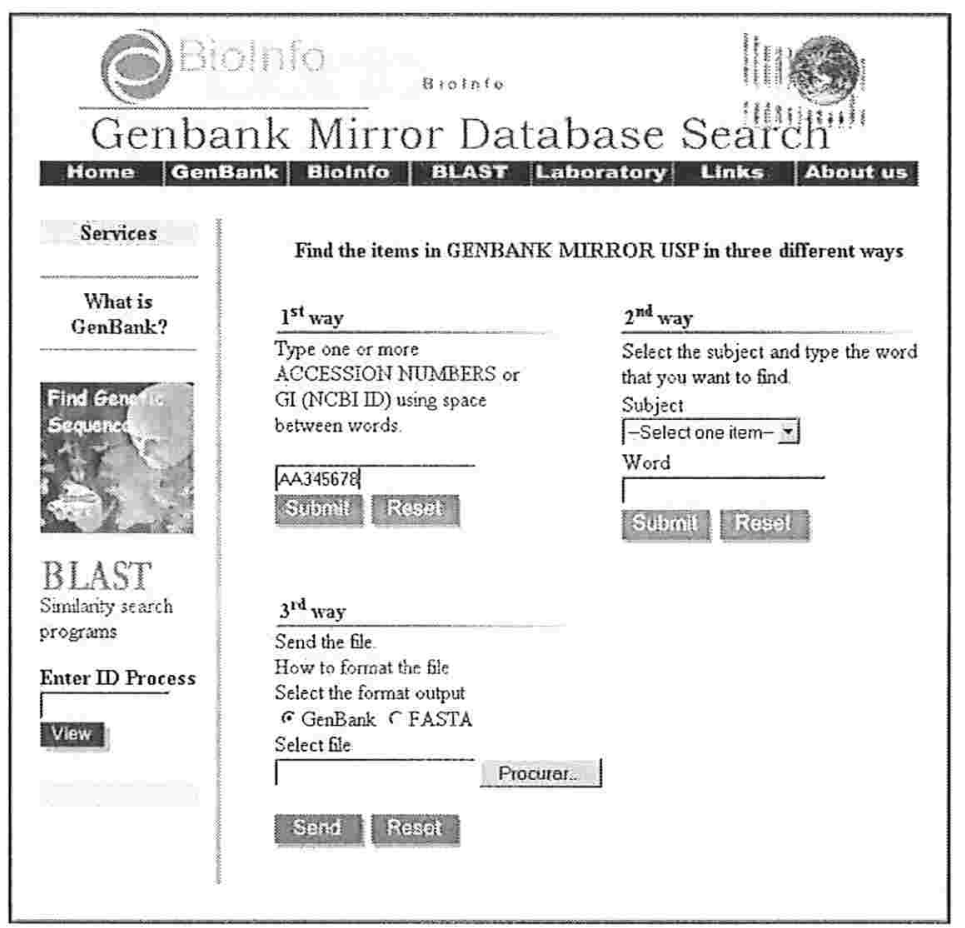

Figura 8: Página de consulta de dados do Genbank Mirror USP (sobre o meta modelo de dados)

\section{Integração de Aplicações de Análise}

Como descrito na seção 2.3 , a proposta principal deste trabalho é modelar e formalizar um mecanismo de integração de aplicações de dados genéticos. Para isso, definiremos algumas classes de elementos

Definição 8 Fluxo de execução é um conjunto de aplicações analíticas, encadeados através de suas entradas e saídas, segundo uma determinada ordem, cuja finalidade é automatizar, total ou parcialmente, tarefas realizadas por cada elemento deste conjunto durante o sequenciamento de amostras. 


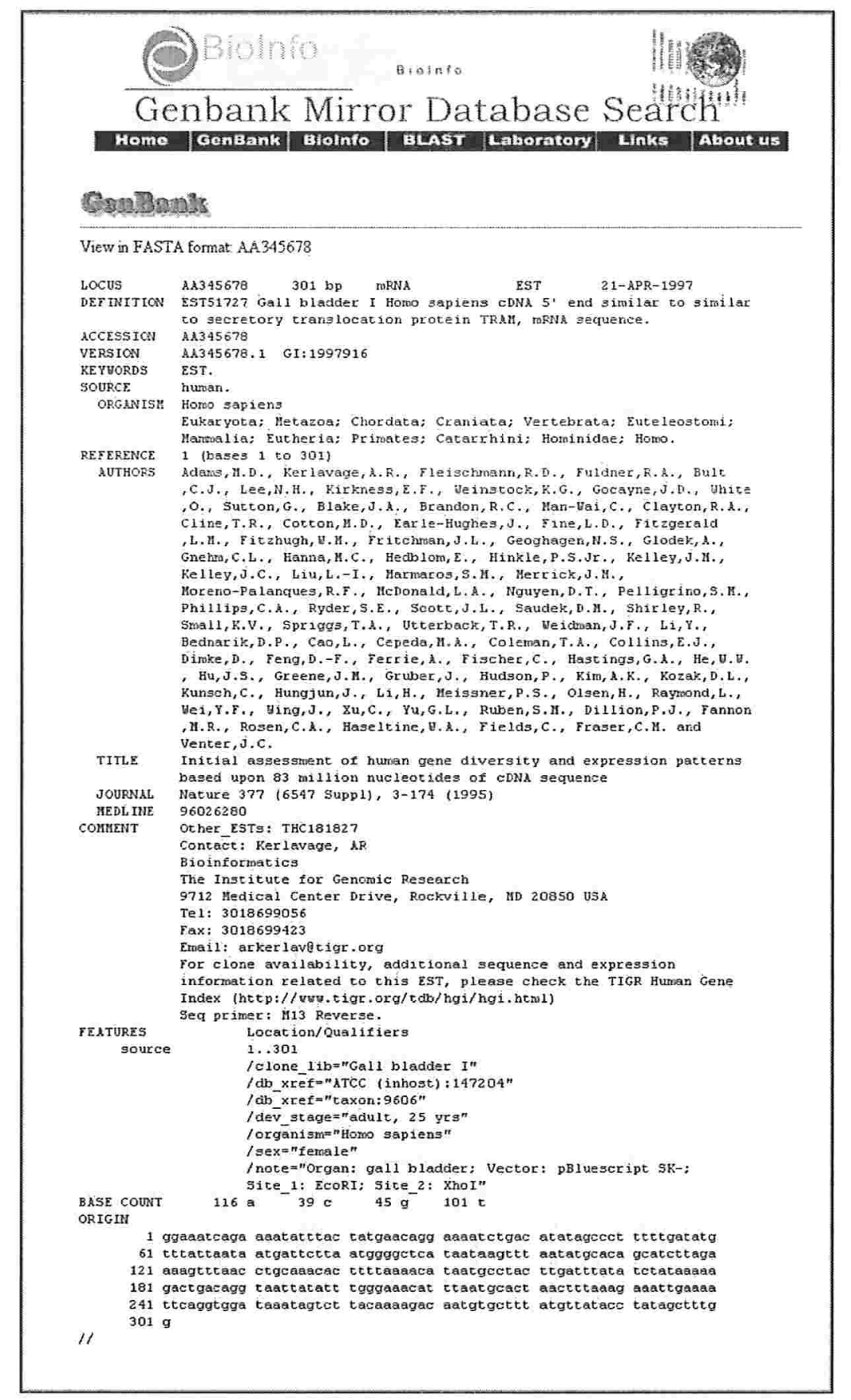

Figura 9: Uma das saídas da consulta de dados no Genbank Mirror USP (resultado de busca sobre o meta modelo de dados) 
O fluxo é dividido em tarefas, onde cada tarefa coincide, em nosso contexo, com uma fase do sequenciamento. Cada tarefa do fluxo é executada por, exatamente, uma única aplicação, como veremos em maiores detalhes na seção seguinte.

O fluxo é válido se:

1. as aplicações são válidas;

2. as aplicações podem ser encadeadas na ordem sugerida;

3. seus resultados parciais ou finais possuem significado semântico relevante no contexto desejado pelo pesquisador.

Os dois primeiros requisitos podem ser avaliados computacionalmente. O último requisito, entretanto, só pode ser validado através da intervenção de um especialista, responsável pelo desenvolvimento do raciocínio lógico do fluxo e, consequentemente, pela validação de sua estrutura e seus resultados.

Definição 9 Tarefa: representa o período de execução de uma aplicação de análise, desde a obtenção de seus dados de entrada até a disponibilização de suas informações de saída. As tarefas são classificadas de acordo com a família de algoritmos usados para resolver o problema associado a cada uma delas. Em nosso estudo inicial, identificamos e listamos as seguintes fases no conjunto $E=\left\{\right.$ base calling ${ }^{6}$ e obtenção de niveis de qualidade, mascaramento de sequências, montagem (assembly), agrupamento de sequências (clustering), busca de similaridade bancos de

\footnotetext{
${ }^{6}$ conversão de imagens de cromatogramas em sequências de nucleotideos (caracteres)
} 
dados, identificação de proteínas e multi-alinhamento, geração de árvores filogenéticas, algoritmos de classificação\}.

Sendo assim, nossa unidade atômica de trabalho será a aplicação, conforme definição 10 . Como dito anteriormente, cada aplicação é responsável pela execução de uma fase do sequenciamento e, consequentemente, de uma tarefa do fluxo.

Definição 10 aplicação analítica: Uma aplicação de análise válida é a implementação de um algoritmo que realiza uma manipulação de dados intimamente associada a alguma das fases pertencentes ao conjunto $E$, usando entradas e produzindo saídas semanticamente coerentes e/ou relevantes. Consideraremos o conjunto $\mathcal{P}$ como conjunto que engloba todas as aplicações de análise válidas no nosso domínio.

Uma aplicação de análise é uma estrutura composta, que possui algumas características complexas. Dessa forma, para construir um modelo genérico dentro de nosso domínio, temos que considerar todas estas características na definição de modelos estruturais, propriedades, operadores e relações de comunicação.

\subsection{Estrutura}

Seja $O_{i d}$ o conjunto de identificadores para as aplicações de análise $P_{i}, P_{i} \in P$.

Seja $P_{i}$ uma aplicação, tal que $P_{i} \in \mathcal{P}$. Estruturalmente, podemos definir uma aplicação $P_{i}$ como uma tupla

$$
P_{i}\left(i d_{i}, t_{i}, h_{i}, \operatorname{param}_{i}, \text { in }_{i}, \text { out }_{i}\right) \text {, }
$$


onde:

- $\underline{i d_{i}}: i d_{i} \in$ Oid, onde Oid é o conjunto de todos os identificadores válidos para $P_{i}$. Cada implementação de um algoritmo $P_{i}$ é mapeado unicamente para um identificador, e viceversa;

- $\underline{t}_{i}$ : é um elemento do conjunto $E$, e indica a tarefa que é implementado por $P_{i}$;

- $\underline{h_{i}}$ : em muitos casos, os algoritmos envolvidos, do tipo $t_{i}$ trabalham com programação dinâmica, mecanismos de indexação ou manipulação de estruturas de dados não-convencionais; em função disso, não é raro encontrarmos implementações heurísticas, que aceleram o processamento dos dados. $h_{i}$ é a heurística adotada para otimizar ou filtrar parcialmente os dados a partir do algoritmo da tarefa $t_{i}$;

- $\operatorname{param}_{i}$ : é uma lista de parâmetros associados à aplicação $P_{i}$. Os parâmetros dependem do tipo do algoritmo e serve para configurar algumas variáveis de execução, tais como grau de qualidade mínimo (ou máximo) do resultado e tipos de formatos de saída (texto, XML, HTML, etc), entre outras;

- $\underline{i n_{i}}$ : é uma lista dos arquivos de entrada usados pela aplicação $P_{i}$. Este atributo indica o número de arquivos de entrada e seus respectivos padrões estruturais. Os padrões estruturais devem ser conhecidos pelo sistema;

- out $_{i}$ : é uma lista dos arquivos de saída gerados pela aplicação $P_{i}$. De forma semelhante ao atributo anterior, este atributo indica o número de arquivos de saída requisitados pela aplicação, juntamente com seus padrões estruturais. 


\subsection{Propriedades}

Uma vez definida a estrutura das aplicações de análise de dados de sequência envolvidos em nosso estudo, podemos definir, também, algumas propriedades.

1. O identificador de um aplicação $P_{i}$ (id) é um valor único. A representação de identificadores através de tipos inteiros se processa porque tipos inteiros são computacionalmente representados de maneira a tornar aplicações de comparação e recuperação mais eficientes, além de permitir cálculos matemáticos, proporcionando possibilidades de geração de novos identificadores através de regras mais simples;

2. Uma aplicação está associado única e exclusivamente a uma das categorias de algoritmos, definida através de sua tarefa;

3. Entradas e saídas necessariamente possuem estruturas fixas. Dessa forma, antes da execução da aplicação, o sistema é capaz de prever quais serão os formatos de entrada e saída de um dada aplicação $P_{i}$. É bom salientar que as estruturas devem ser fixas, e não necessariamente padronizadas, ou seja, a aplicação pode adotar mais de um formato de entrada (ou saída), mas o sistema deve ser capaz de identificar, com antecedência, qual será a estrutura escolhida;

4. O tipo da aplicação determina a fase em que ele será executado dentro do fluxo. O tipo de aplicação $P_{i}\left(t_{i}\right)$, identifica qual a família de algoritmos implementada por $P_{i}$. 


\subsection{Operadores}

Com o domínio da estrutura e das propriedades aplicadas sobre as aplicações analíticas, somos capazes de definir operadores. Os operadores representam relações entre aplicações e serão a base para a construção dos fluxos.

Trabalharemos com quatro operadores, que sustentarão a definição de um método alternativo de integração através do mapeamento das relações entre as aplicações. Desses operadores, três estão intimamente ligados a aspectos estruturais, permitindo classificá-los como operadores sintáticos: operadores de precedência, equivalência de formatos e encadeamento. O outro operador, por outro lado, está ligado a aspectos semânticos, dependentes do domínio de pesquisa e de responsabilidade do pesquisador: operador de equivalência de aplicações.

\subsubsection{Operador de Precedência}

Definição 11 : Operador <: O operador <é uma função $f: \mathcal{P} \times \mathcal{P} \rightarrow\{$ true, false $\}$.

Sejam $a$ e $b$ aplicações válidas. Falamos que $a<b$ (ou a precede b) se $a$ e $b$ possuem tipos distintos e o tipo da aplicação a indica uma fase de execução anterior à fase indicada pelo tipo da aplicação b;

A relação <, acima definida, é transitiva, ou seja, dadas três aplicações $a, b$ e $c$. Se $a<b$ e $b<c$, então $a<c$.

Prova 1 Sejam três aplicações $a, b$ e $c$. Provaremos que, se $a<b$ e $b<c \Rightarrow a<c$.

Dados $a<b$ (I) e $b<c$ (II), suponha que $a<c=$ falso (III), ou seja, a não é executado antes de c. Sendo assim, podemos dizer que $a<b=$ falso, por (III) e (II) pois $b<c$. Entretanto, 
$a<b=$ falso é uma contradição, pois assumimos anteriormente que $a<b$ e $b<c$.

\subsubsection{Operador de Equivalência de Formatos}

Definição $12:$ Operador $\approx$. O operador $\approx$ é uma função $f:$ in $\times$ in $\rightarrow\{$ true, false $\}$.

Sejam a e b formatos estruturados. Falamos que $a \approx b$ (ou a é equivalente $a$ b) se a possui significado semântico igual a b, sendo possivel converter, estruturalmente, a para $b$ e vice-versa.

Sendo assim, $a$ e $b$ devem pertecer ao mesmo domínio. Além disso cada componente da estrutura do formato $a$ deve possuir um equivalente na estrutura do formato $b$, e vice-versa.

\subsubsection{Operador de Encadeamento}

Definição $13:$ Operador $\rightarrow$ O operador $\rightarrow$ é uma função $f: \mathcal{P} \times \mathcal{P} \rightarrow\{$ true, false $\}$.

Sejam a e $b$ aplicações válidas. Falamos que $a \rightarrow b$ (ou a encadeia $b$ ) se $a<b, t_{a}=t_{b} e$ out $_{a} \approx i n_{b}$

Sendo assim, $a$ e $b$ são ditos encadeáveis se podemos executá-los em sequência, aproveitando a saída de $a$ como entrada (ou uma das entradas) para $b$, abstraindo restrições estruturais dos formatos dos arquivos de saída e entrada de $a$ e $b$, respectivamente.

\subsubsection{Operador de Equivalência de Aplicações}

Definição $14:$ Operador $\simeq$. O operador $\simeq$ é uma função $f: \mathcal{P} \times \mathcal{P} \rightarrow\{$ true, false $\}$.

Sejam a e b aplicações válidas. Falamos que $a \simeq b$ (ou a é equivalente $a$ b) se $a$ e $b$ são do mesmo tipo e, além disso, se as entradas e saídas de a e b são semanticamente equivalentes. 
Na definição de equivalência semântica, não possuímos, atualmente, condições de formular relações matemáticas, uma vez que muitas aplicações de análise são dependentes da semântica definida pelo usuário pesquisador. Trabalharemos com a relação entre aplicações, com a informação de seu caráter semântico conhecida de antemão, mas a definição de quais aplicações são equivalentes, ou não, depende do conhecimento semântico de domínio, de responsabilidade do pesquisador.

Uma vez que conseguimos definir a estrutura, as propriedades e os operadores, podemos fazer comparações entre as aplicações. Podemos, desta maneira, definir aplicações compatíveis, comparáveis e encadeáveis, conforme subseções $4.4 .1,4.4 .2$ e 4.4 .3 .

\subsection{Relacionamentos e Comunicação}

Uma vez definidos estrutura, propriedades e operadores de aplicações, é necessário definir suas relações lógicas e seus mecanismos de comunicação. Dessa maneira, podemos classificar aplicações de acordo com suas relações. Além disso, é possível definir regras e restrições de comunicação baseados em suas propriedades e representados através de seus operadores.

Inicialmente, classificamos as aplicações em três categorias não-exclusivas: aplicações compatíveis, comparáveis e encadeáveis, que veremos com maiores detalhes a seguir.

\subsubsection{Aplicações Compatíveis}

Definição 15 Aplicações compatíveis. Sejam duas aplicações $P_{i}$ e $P_{j}$, tal que $P_{i}, P_{j} \in \mathcal{P}$. $P_{i}$ e $P_{j}$ são ditos compativeis se $i d_{i}=i d_{j}, h_{i}=h_{j}, t_{i}=t_{j}$ e $\operatorname{param}_{i}=\operatorname{param}_{j}$. 
Duas aplicações são ditas compatíveis se possuem o mesmo identificador, o mesmo tipo, os mesmos parâmetros e aplicam a mesma heurística. Aplicações compatíveis possuem a mesma fase de execução, executam o mesmo algoritmo, segundo uma única heurística e de acordo com os mesmos parâmetros de configuração. Esta situação ocorre quando se deseja fazer comparações entre aplicações que aplicam a mesma implementação em entradas de dados semanticamente distintas.

As aplicações compatíveis cobrem a variação de parâmetros utilizada sobre a mesma aplicação. O objetivo deste conjunto é avaliar a variação dos resultados de acordo com a variação de seus parâmetros.

Em várias áreas de pesquisa, Biologia Molecular em particular, o valor das comparações entre experimentos é muito grande. Como uma ciência baseada em observações, é de grande interesse analisar o comportamento de determinados experimentos diante de variações de condições ambientais.

Devido à importância deste conjunto, julgamos conveniente tratar as aplicações com esta característica como um conjunto diferenciado.

\subsubsection{Aplicações Comparáveis}

Definição 16 Aplicações comparáveis. Sejam duas aplicações $P_{i}$ e $P_{j}$, tal que $P_{i}, P_{j} \in \mathcal{P}$. $P_{i}$ e $P_{j}$ são ditas comparáveis se $t_{i}=t_{j}$, param $_{i}=\operatorname{param}_{j}, i n_{i}=i n_{j}$ e out ${ }_{i}=$ out $_{j}$.

Duas aplicações são ditas comparáveis se pertencem à mesma fase de execução e se aplicam a conjuntos de dados semanticamente iguais, usando os mesmos parâmetros e, consequentemente, 
gerando resultados semanticamente iguais.

Não é raro encontrar situações onde se deseja fazer comparações entre os resultados gerados por heurísticas diferentes aplicadas ao mesmo algoritmo. Aplicações comparáveis fornecem subsídios maiores para a avaliação dos níveis de qualidade dos resultados baseado nas heurísticas usadas. Dessa maneira, é possível avaliar melhor o grau de qualidade dos dados e obter informação relevante para tomada de decisão.

Podemos ter aplicações compatíveis e comparáveis, mas isto representa um caso muito particular dentro do conjunto de aplicações. Para que duas aplicações sejam, ao mesmo tempo, compatíveis e comparáveis, devem implementar a mesma heurística e devem utilizar os mesmos padrões estruturais e semânticos de entrada e saída de dados. Dessa forma, se duas aplicações $P_{i}$ e $P_{j}$, com $P_{i} \in \mathcal{P}$ e $P_{j} \in \mathcal{P}$, teremos $P_{i}$ e $P_{j}$ compatíveis, e $P_{i}$ e $P_{j}$ comparáveis se, e somente se $P_{i}=P_{j}$

Prova 2 Sejam $P_{i}$ e $P_{j}$ aplicações, tais que $P_{i}, P_{j} \in \mathcal{P}$. Provaremos que $P_{i}$ e $P_{j}$ são compatíveis e comparáveis se, e somente se, $P_{i}=P_{j}$.

(I) Considere que existam duas aplicações $P_{i}$ e $P_{j}$, tais que $P_{i}$ e $P_{j}$ são compativeis e comparáveis, mas $P_{i} \neq P_{j}$. Se $P_{i}$ e $P_{j}$ são compatíveis, então $i d_{i}=i d_{j}, h_{i}=h_{j}, t_{i}=t_{j} e$ param $_{i}=$ param $_{j}$. Se $P_{i}$ e $P_{j}$ são comparáveis, então $i n_{i}=i n_{j}$ e out $t_{i}=$ out $_{j}$. Sendo assim, todos os itens de $P_{i}$ e $P_{j}$ säo iguais, consequentemente $P_{i}=P_{j}$, o que é uma contradição, pois assumimos que $P_{i} \neq P_{j}$.

(II) Considere que $P_{i}$ e $P_{j}$ são aplicações tais que $P_{i}=P_{j}$, entretanto $P_{i}$ e $P_{j}$ ou não são 
compativeis, ou não são comparáveis, ou ambos.

Se $P_{i}=P_{j}$, então necessariamente,

a) $i d_{i}=i d_{j}$

b) $h_{i}=h_{j}$,

c) $t_{i}=t_{j}$

d) $\operatorname{param}_{i}=\operatorname{param}_{j}$,

e) $i n_{i}=i n_{j}$

f) out $_{i}=$ out $_{j}$.

Por a), b), c) e d), temos que $P_{i}$ e $P_{j}$ são compativeis. Por $c$ ), d), e) e f), $P_{i}$ e $P_{j}$ são comparáveis. Dessa forma, temos que, se $P_{i}=P_{j}$, necessariamente $P_{i}$ e $P_{j}$ são compatíveis e comparáveis, o que é uma contradição, pois assumimos anteriormente que ou $P_{i}$ e $P_{j}$ não são compativeis, ou não são comparáveis, ou ambos.

Por (I) e (II), provamos que $P_{i}$ e $P_{j}$ são compativeis e comparáveis se, e somente se, $P_{i}=P_{j}$

\subsubsection{Aplicações Encadeáveis}

Definição 17 Aplicações encadeáveis Sejam duas aplicações $P_{i}$ e $P_{j}$, tal que $P_{i} \in \mathcal{P}$ e $P_{j} \in$ P. $P_{i}$ e $P_{j}$ são ditas encadeáveis se a relaçãa $P_{i} \rightarrow P_{j}$ é válida.

O encadeamento de aplicações é a relacão chave para nosso sistema de integracão. Esta é uma relação muito particular, pois não é reflexiva, nem comutativa, nem associativa, nem transitiva. 
A relação de encadeamento está fortemente ligada aos padrōes estruturais de entrada e saída das aplicações analíticas usadas. Tais padrões ditam os conjuntos de aplicações que podem, ou não, ser encadeados. Por este motivo, muitas das propriedades desta relação não podem ser totalmente garantidas.

Note que a relação de encadeamento sugere um nível de ordenação definido entre as aplicações. 


\section{Integração através de Fluxos}

A integração por fluxos representa a ligação entre os mecanismos utilizados para integrar dados e aplicações. Antes de comentar detalhes sobre o método de gerenciamento de fluxo propriamente dito, é necessário destacar especial atenção a um tópico de grande importância em nossa estrutura: a padronização de formatos.

Como dissemos anteriormente, trabalhamos com as aplicações disponíveis por vários grupos de pesquisa como caixas-pretas. Dessa forma, não poderemos intervir de forma direta em suas estruturas de entrada/saída; entretanto, é possível trabalhá-las de forma indireta, adotando um meio de conversão de formatos que mapeie os respectivos formatos de entrada e saída entre si.

Esta abordagem deixa o sistema altamente dependente da parte estrutural dos processos. Dessa forma, teríamos que mapear todos os formatos entre si, construindo wrappers de conversão para cada ligação de uma aplicação $P_{i}$ com uma aplicação $P_{j}$. Imagine que temos $n$ aplicações funcionando em nosso sistema. Se, por exemplo, uma aplicação $P_{k}$ qualquer for atualizada e, além disso, em sua nova versão, $P_{k}$ apresente alterações em seu formato de entrada e/ou de saída, teremos que reconstruir $n-1$ wrappers de formatos.

Esta solução não é ideal, pois sua manutenção pode ser difícil e de pouca flexibilidade. Por este motivo, apelaremos para uma solução alternativa, onde utilizaremos um formato intermediário, que servirá como base para a construção dos wrappers. O objetivo deste formato intermediário é reduzir o número de conversões necessárias em manutenções. Para isso, usaremos XML, que possui ferramentas que facilitarão o trabalho na busca deste objetivo. 


\subsection{XML}

XML (Extensible Markup Language) é uma meta linguagem utilizada para estruturação de documentos, derivada do SGML (Standard Generalized Markup Language). Chamamos XML de meta linguagem porque ela é usada para definir outras linguagens, que efetivamente, serão responsáveis pelo reconhecimento semântico do papel de cada item de dado dentro do documento. Para isso, XML possui um vocabulário específico (rótulos de cada elemento da linguagem) e sintaxe de declaração (gramática que dita o comportamento semântico de cada elemento da linguagem, bem como suas relações) $[53,54]$.

A maioria dos documentos trabalha com dados que podem ser agrupados de acordo com sua informação semântica. Esta informação normalmente é fruto da incorporação de regras de negócio nos dados. A natureza destes dados nos leva a analisar seu conteúdo e seu papel dentro de nosso domínio. Neste caso, falamos que nossos dados refletem uma "informação estruturada". Este é o ambiente mais indicado para a utilização de uma linguagem com XML, que facilita a identificação e manipulação da informação, adotando uma estrutura padronizada para nossos documentos.

HTML (Hyper Text Markup Language), a exemplo de XML, também é uma linguagem derivada de SGML, cujo objetivo é facilitar a estruturação de documentos. A principal diferença é que HTML não possibilita a incorporação de informações semânticas nos dados, limitando-se somente a trabalhar com primitivas de visualização destes.

As principais vantagens de XML, para nossa abordagem, são:

- padronização: XML é uma linguagem de padronização aberta, coordenada pelo consórcio 
W3C, e independente de plataforma de software. A adoção de uma linguagem padronizada fornece maior poder de compartilhamento de informação entre sistemas de informação de diferentes origens;

- valores significativos: XML permite a inclusão de chaves significativas para os dados que desejamos estruturar. Isto possibilita a elaboração de mecanismos de busca mais eficientes e eficazes, além de personalizar a aplicação agregando maior valor semântico a elementos de maior importância no modelo;

- flexibilidade: a flexibilidade fornecida pela linguagem, através da utilização de chaves mnemônicas, possibilita a manipulação de estruturas legadas, que não mantêm vínculos físicos para a troca de informação;

- recursos de programação: atualmente, existe uma grande disponibilidade de recursos de desenvolvimento de aplicativos que usam XML, como tradutores, ambientes integrados de compilação e tradução, bibliotecas de funções de manipulação de dados, bancos de dados, servidores web, etc.

- integração com a internet: existe uma visível tendência de que XML se torne um padrão para aplicações web.

- escalabilidade: documentos XML são, de maneira geral, escaláveis, pois XML permite a definição de estruturas autônomas, que compõem outras estruturas mais complexas. Podemos imaginar documentos XML através de uma estrutura de árvore, onde existe uma hierarquia entre os elementos. 
Utilizando XML, o sistema trabalhará com um número menor de wrappers. Além disso, a própria construção destes poderá ter uma complexidade menor, uma vez que a relação refletida pelo wrapper deixa de ser estrutura $\leftrightarrow$ estrutura, para estrutura $\leftrightarrow$ semântica. Isto porque podemos agregar valor semântico a elementos do documento XML, assim como modelamos a situação real.

\subsection{Fluxos de Execução Genéricos (Gen-Pipe)}

Nas seções anteriores, definimos aspectos estruturais das aplicações, tratando-as como entidades complexas. Além disso, estudamos suas propriedades, identificamos algumas relações e definimos alguns operadores. Agora, temos ferramentas suficientes para construir um mecanismo de integração baseado em aplicações de análise de dados.

Gerenciamento de fluxo de execução é o método de processamento em que uma tarefa is realizada em fases, onde a saída de um estágio serve de entrada para o estágio seguinte. Esta técnica é muito utilizada em Computação Paralela para melhoria de desempenho, uma vez que permite que várias partes de diferentes tarefas possam ser executadas ao mesmo tempo. A idéia de utilização do fluxo é uma evolução natural da automatização da aplicação de sequenciamento, considerando o caráter sequencial das aplicações e a existência de estruturas estáticas de entrada e saída (arquivos) que permitem o seu encadeamento. Ao contrário dos objetivos acima, a escolha do fluxo não se deve à sua melhoria de desempenho, mas à sua capacidade de integração de tarefas através de relações de encadeamentos.

Obedecendo à ordem de fases do sequenciamento, detalhada anteriormente, podemos utilizar o operador de encadeamento para verificar se duas aplicações podem ou não ser encadeadas, 
gerando um fluxo parcial válido.

Esta abordagem permite a definição de fluxos parciais, ou seja, a construção do fluxo independe da cobertura de todas as fases de execução. Podemos ter fluxos que iniciam (ou terminam) em qualquer uma das fases de execução, desde que a relação de encademento seja preservada. Esta abordagem se mostra extremamente conveniente, uma vez que há casos em que não dispomos de dados em sua forma primitiva para iniciar a análise, ou o experimento trabalha com resultados intermediários.

Dessa forma, podemos até definir uma relação de encadeamento de fluxos, que é uma consequência direta da relação de encadeamento de aplicações.

A principal vantagem do sistema de edição de fluxos, sugerido neste trabalho, é a automatização das fases de sequenciamento. Um arquivo gerado em uma fase pode ser usado na fase seguinte, mesmo que possua incompatibilidade estrutural. Pela operação de encadeamento, sabemos que o arquivo de saída de uma fase e o arquivo de entrada da fase seguinte devem ter o mesmo conteúdo semântico. Sendo assim, variações estruturais podem ser contornadas com a definição de um wrapper (ver figura 2).

Além disso, as aplicações podem ser locais ou remotas, e o acesso é feito a partir de primitivas de sistema operacional. Cada aplicação possui uma entrada em um mapa de aplicações, que armazena sua localização, sua fase de execução e uma lista de wrappers responsáveis pela adaptação de seus arquivos de entrada.

A implementação do sistema é feita externamente, através de drivers de conexão a sistemas gerenciadores de bancos de dados. Esta abordagem toma a arquitetura flexível em relação ao 
SGBD utilizado e à linguagem de implementação do sistema, entretanto apresenta desvantagens em relação a desempenho, uma vez que todo a aplicação de comunicação de dados é feita através de mecanismos de software externos ao gerenciador.

O editor de fluxos é, na verdade, um mecanismo de configuração de aplicações que se baseia em relações (como encadeamento e precedência) e propriedades. A configuração das aplicações poderá acontecer em tempo de execução, através de um módulo de recompilação de seus atributos.

O editor de fluxos funcionará como uma estrutura de edição e armazenamento de filas de aplicações. Do ponto de vista lógico, temos uma lista de filas de aplicações, ou seja, armazenamos nossos fluxos em uma lista, onde sua configuração é um dado persistente. Cada elemento desta lista é uma fila de aplicações, previamente cadastrada pelo usuário.

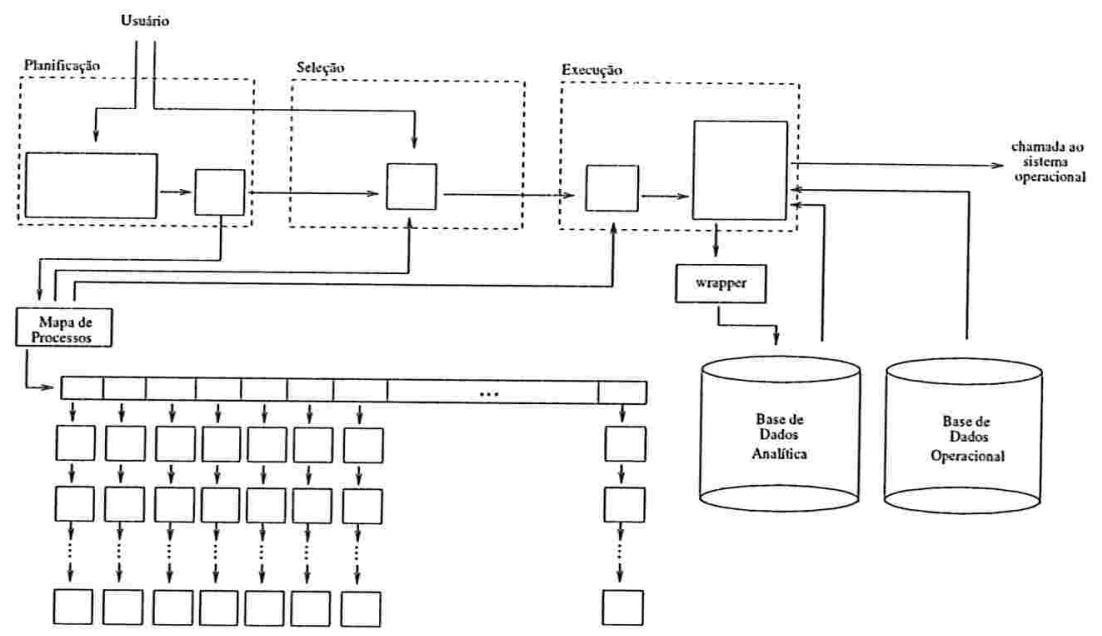

Figura 10: Esquema lógico do editor de fluxos

Note que, pela figura 10 , podemos separar a aplicação de utilização do fluxo em três fases distintas: planificação, seleção e execução. 
A planificação representa a fase de configuração. Nesta fase ocorre, efetivamente, a edição do fluxo. O usuário cadastra as aplicações individualmente, configurando seus parâmetros de execução. No encadeamento de cada aplicação, existe um módulo associado que verifica propriedades de encadeamento e precedência, para garantir a integridade do fluxo. Uma vez finalizado o fluxo, ele é adicionado à lista virtual, juntamente com uma chave de identificação, para possibilitar sua posterior recuperação pelo sistema.

A seleção consiste na aplicação de recuperação de um fluxo já cadastrado no sistema. Cacla fluxo possui um identificador local único, utilizado como chave de busca. Na requisição de uma aplicação, a lista de fluxos é percorrida até a localização da lista de aplicações. Um apontador lógico para o fluxo é devolvido após a busca.

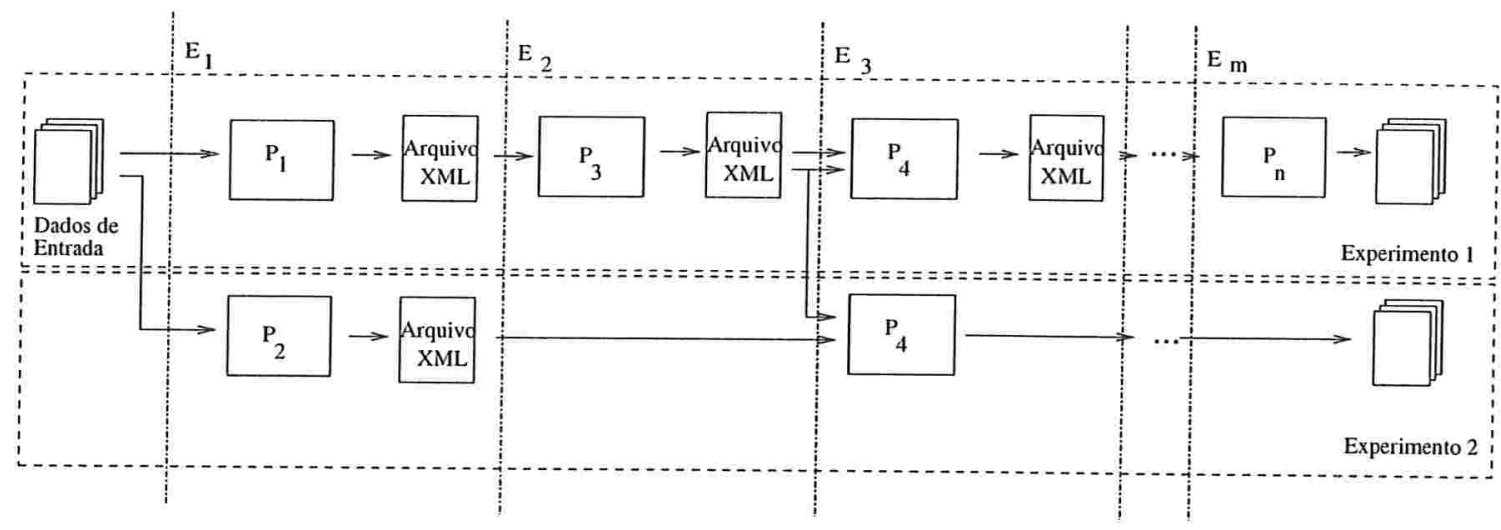

Figura 11: Fluxo genérico - GenPipe

Finalmente, a execução é a última fase. Uma vez selecionado o fluxo, ele é recuperado, com suas configurações iniciais, inclusive. Nesta fase, a fila é percorrida iterativamente, retirando a aplicação de seu início a cada iteração, até que a aplicação no final da fila seja executada. 
A execução de uma aplicação consiste na (re)compilação da estrutura de fluxo, busca de seus dados de entrada, que pode ser feita diretamente sobre a base de dados operacional ou analítica, seguida da formatação de sua entrada, realizada através de um wrapper, da recompilação de seus parâmetros, que podem ser modificados pelos usuários e pela chamada da aplicação por parte do sistema operacional.

Podemos ver um esquema ilustrativo de execução do fluxo na figura 11. Veja que cada aplicação possui uma tarefa específica e que, de acordo com esta tarefa, podemos classificar a atividade e identificar os formatos de entrada/saída. Ao final de cada tarefa, um wrapper realiza a conversão de formatos para uma arquivo XML e, de forma semelhante, antes do início de cada tarefa (exceção à primeira), um outro wrapper faz o serviço inverso.

\subsection{Estudo de Caso}

Ilustraremos a utilização de nossa arquitetura de integração através de um estudo de caso para identificação de tipos e regiões de sequências de HIV (vírus da imunodeficiência humana), vírus que causa a AIDS (síndrome da imunodeficiência humana). Este é um problema real e que pode ser resolvido através da utilização de um fluxo.

Para nosso experimento, utilizaremos as seguintes aplicações:

- BLAST - Basic Local Alignment Search Tool: BLAST $[55,56]$ é um conjunto de programas heurísticos para busca de similaridade em conjuntos de dados de proteína e DNA;

- Phylip: Phylip [57] é um pacote de programas para análise de inferência filogenética (árvores filogenéticas) distribuído por Joe Felsentein. Os programas deste pacote utilizam os 
métodos de parsimônia, matriz de distâncias e máxima verossimilhança, utilizando ainda bootstraping e árvores de consenso. O phylip trabalha com sequências moleculares, frequências de genes, sítios de restrição, matrizes de distância e caracteres discretos 0/1;

- Clustalw: Clustalw [58, 59] é um software de alinhamento de sequências de DNA e proteínas. Ele produz alinhamentos significativos de múltiplas sequências, calculando o melhor casamento de padrão e as alinha a partir de suas similaridades, identidades e diferenças.

O primeiro passo para conduzir pesquisas com amostras de HIV, ou a maioria das patologias, é identificar grupos de afinidades funcionais. Como virus são organismos que se modificam com grande facilidade e rapidez, é de grande interesse buscar meios de classificação das populações. A identificação destes tipos indicará os melhores tipos de tratamento para os pacientes.

Uma vez coletadas as amostras dos pacientes, temos que extrair as sequências dos vírus. $\mathrm{O}$ arquivo com as sequências obtidas é a entrada inicial para nosso sistema. Em alguns casos, quando não temos os arquivos de sequências em formato texto, podemos utilizar as próprias imagens de cromatograma das sequências como entrada inicial do sistema de edição de fluxo.

Primeiramente, faremos um alinhamento local, usando BLAST, para identificar qual a região do vírus que foi sequenciada. Para isto, parametrizaremos o software para a utilizar um banco de dados do HXB2 (sequência referência do vírus HIV) [60]. O arquivo de saída deste programa será formatado, por um wrapper, para um arquivo XML.

O resultado gerado pelo alinhamento nos fornece uma indicação da região da qual foi extraída a sequência. Além disso, a avaliação da qualidade do casamento de padrão pode nos confirmar a natureza da amostra e indicar possíveis falhas ocorridas durante a fase anterior. 


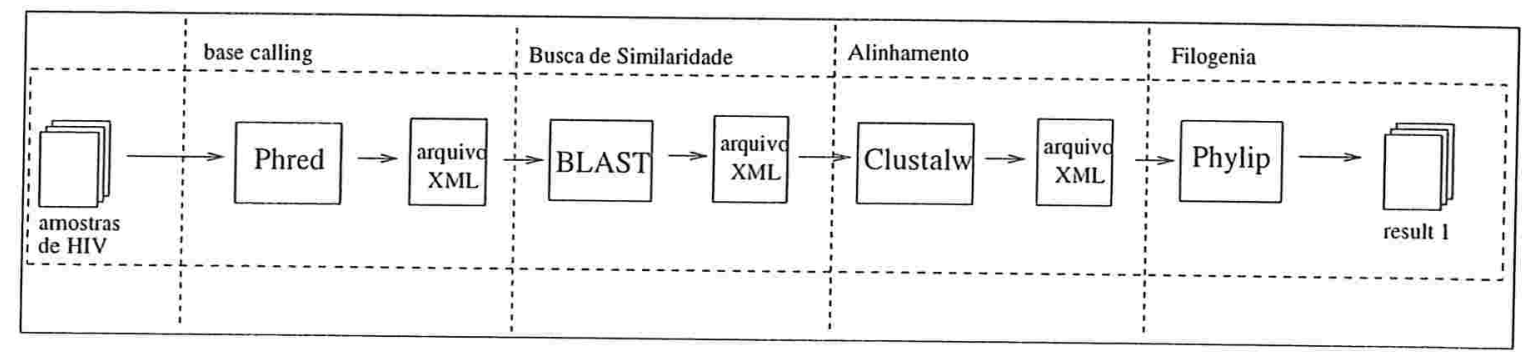

Figura 12: Fluxo de genotipagem de HIV

Além da região, estamos interessados no tipo de vírus que infectou os pacientes. Podemos conseguir esta informação através de alinhamentos com sequências representantes de cada tipo, e sub-tipo se for o caso. Podemos realizar o alinhamento novamente com o BLAST, variando seu parâmetro de banco de dados para representantes de tipos de HIV.

Do ponto de vista de sistema, um wrapper recupera o arquivo gerado na fase anterior e realiza uma conversão para o formato FASTA [61], necessário para a entrada de dados no programa.

Novamente, o resultado gerado nos fornece uma indicação do tipo de vírus com o qual estamos trabalhando. Esta indicação será de extrema utilidade durante o tratamento da doença e, além disso, pode indicar evidências durante a fase de pesquisa.

Há casos, entretanto, em que a região trabalhada é conservada em relação a dois tipos de vírus diferentes. Neste caso, é necessário realizar um estudo mais detalhado para avaliar qual dos tipos é o mais similar à nossa amostra, ou se podemos estar trabalhando com um novo tipo de vírus.

Podemos chegar a estas respostas através de análise filogenética. Inicialmente, precisamos fazer um alinhamento múltiplo de sequências, utilizando amostras de dados do experimento 
anterior. Uma vez processado o alinhamento múltiplo, poderemos utilizá-lo para processar a árvore filogenética mais adequada para nosso experimento.

Passaremos para a geração de árvores filogenéticas, usando o Phylip. O cálculo das árvores pode ser feito a partir de três métodos: matriz de distâncias, parsimônia e máxima verossimilhança. Estes métodos utilizam ferramentas estatísticas para agrupar nossas sequências de acordo com seus níveis de similaridade, produzindo uma árvore de relações.

Temos uma demostração da sequência de passos desde a edição dos módulos até a finalização do processo de análise, ilustrados nas figuras 13 até 20 .

Primeiramente, planejamos qual será a ordem de execução das tarefas 13 e 14 . Note que a interface permite a integração de vários programas, de forma dinâmica, onde o usuário edita, em tempo de execução, a sequência de tarefas do infopipe.

O sistema possui um agente de verificação de consistência do infopipe. O papel deste agente é identificar falhas ocorridas durante a edição do fluxo. De acordo com as definições vistas na seção anterior, vimos que há uma sequência lógica de execução para as tarefas, direcionando para a definição de um nível de escalonamento. Apesar da dinamicidade e do grande número de possibilidades de experimentos, é possível identificar combinações de encadeamento que não fazem sentido para o pesquisador.

Após a edição e validação do infopipe, temos que definir quais serão os parâmetros de execução para cada tarefa, ilustrado na figura 15.

Uma vez definidos os parâmetros, temos que preparar a entrada inicial dos dados. Neste momento, o sistema abre uma tela de seleção de bancos de dados (figura 16), onde podemos 


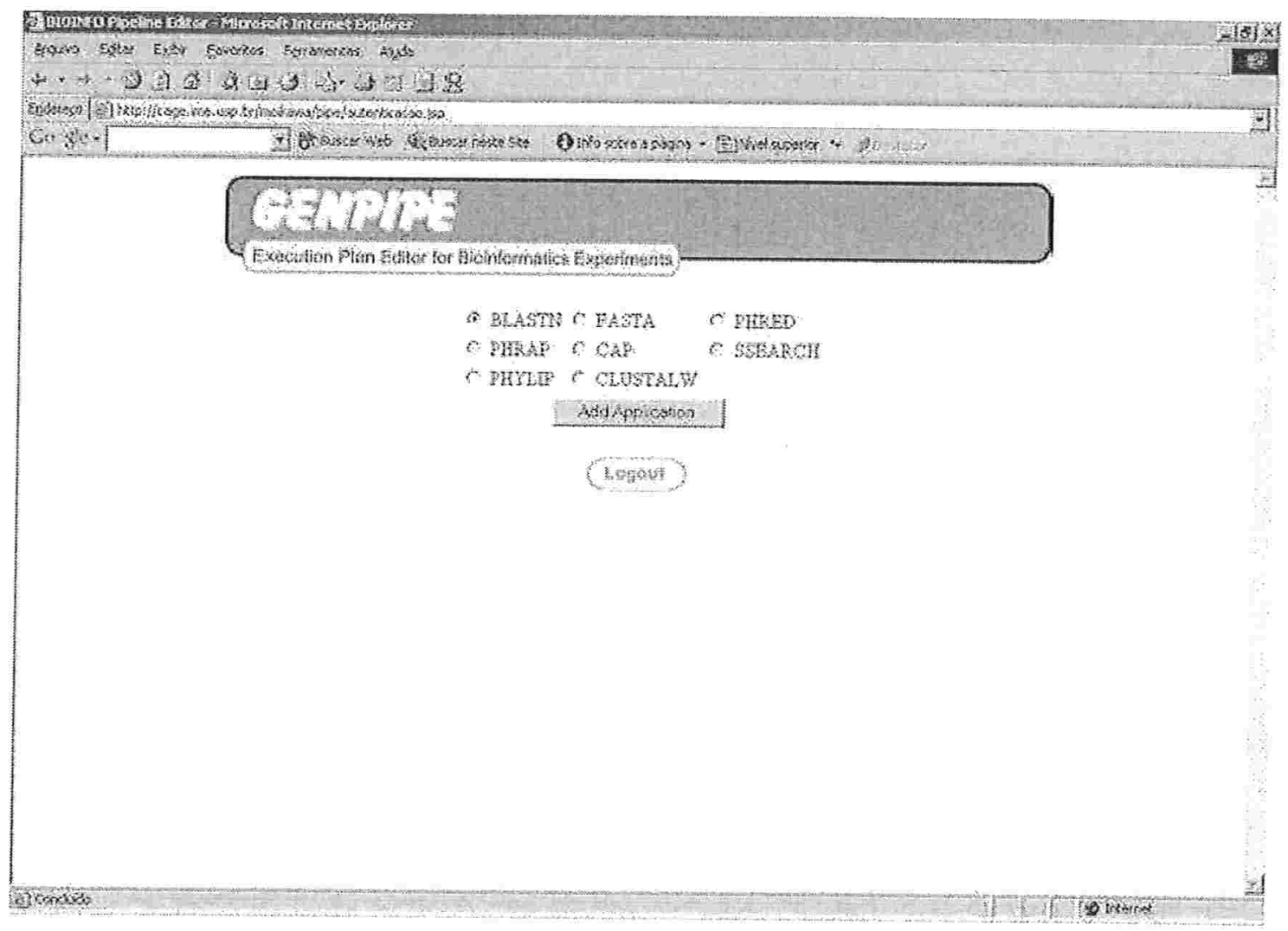

Figura 13: Tela de planejamento de execução

escolher a fonte de nossos dados de entrada.

Escolhida a fonte de dados, identificamos os registros que alimentarão a entrada no infopipe, nas figuras 17 e 18 .

Neste momento, temos todos os requisitọ necessários para iniciar a execução do nosso fluxo de tarefas. A nossa interface permite o acompanhamento das tarefas realizadas passo-a-passo através de nossa interface. Ao final da execução de cada tarefa, é possível visualizar a interface de saída dos dados. 


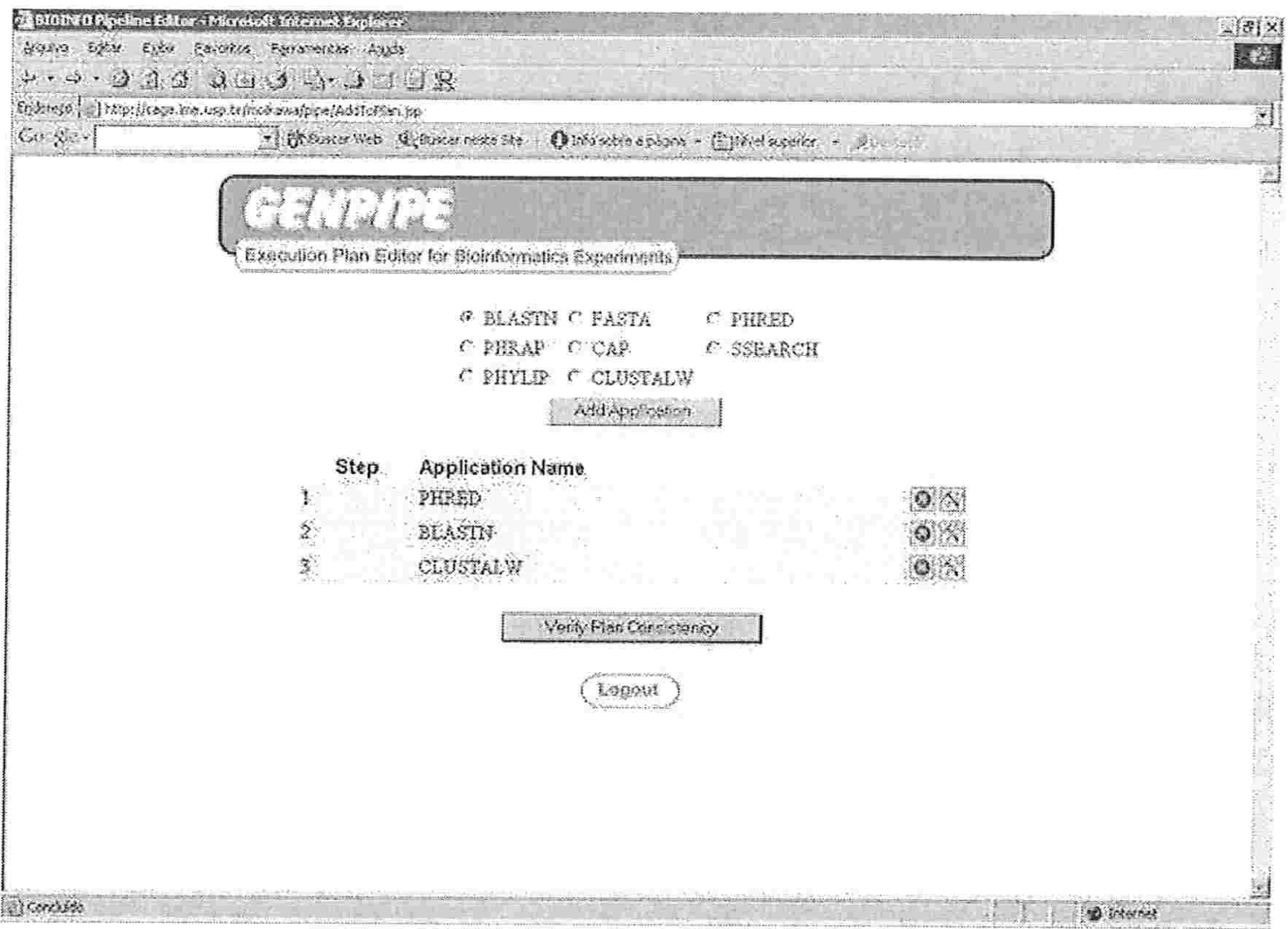

Figura 14: Tela com execução planejada 


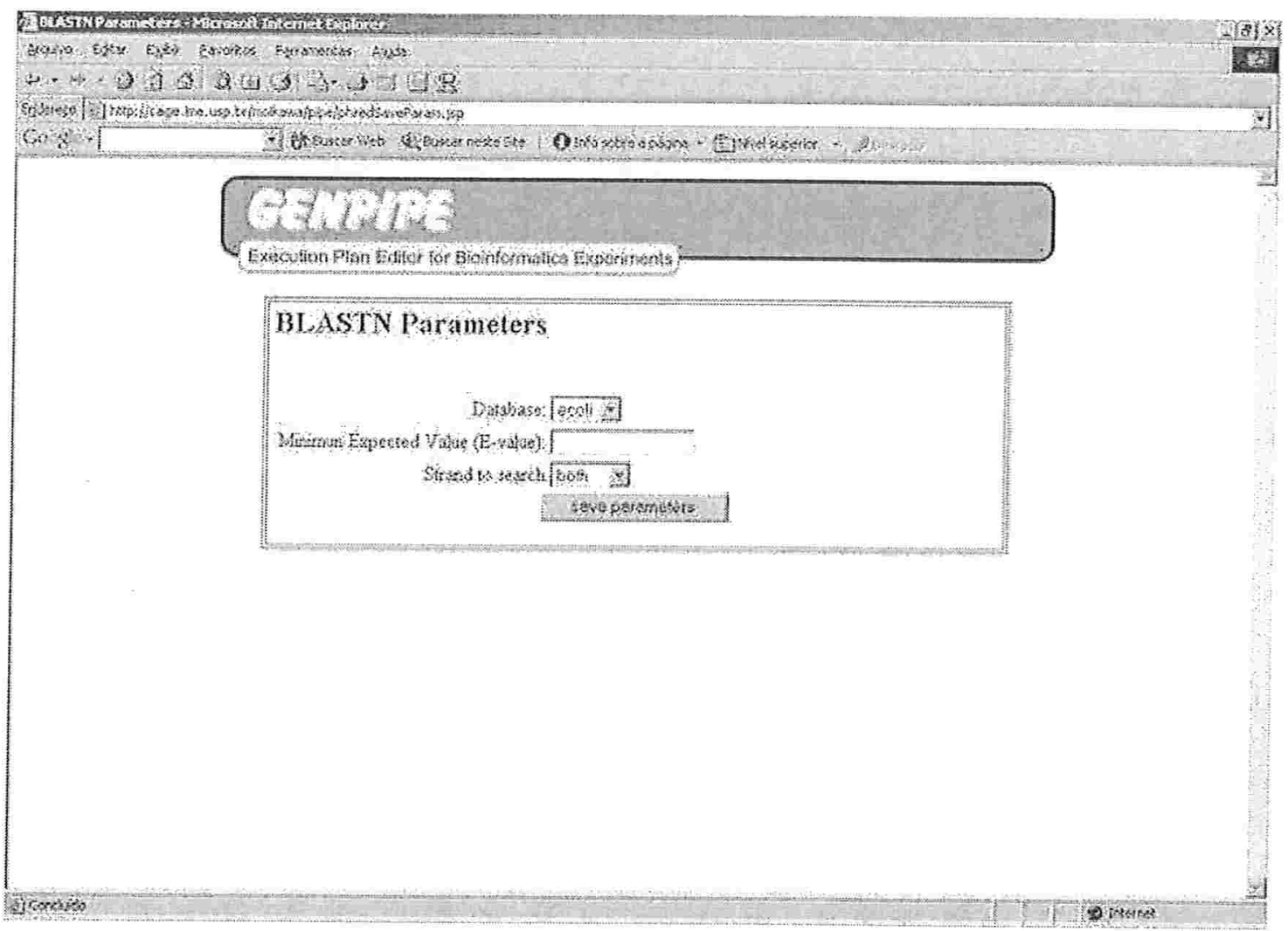

Figura 15: Edição de parâmetros para cada tarefa do infopipe 


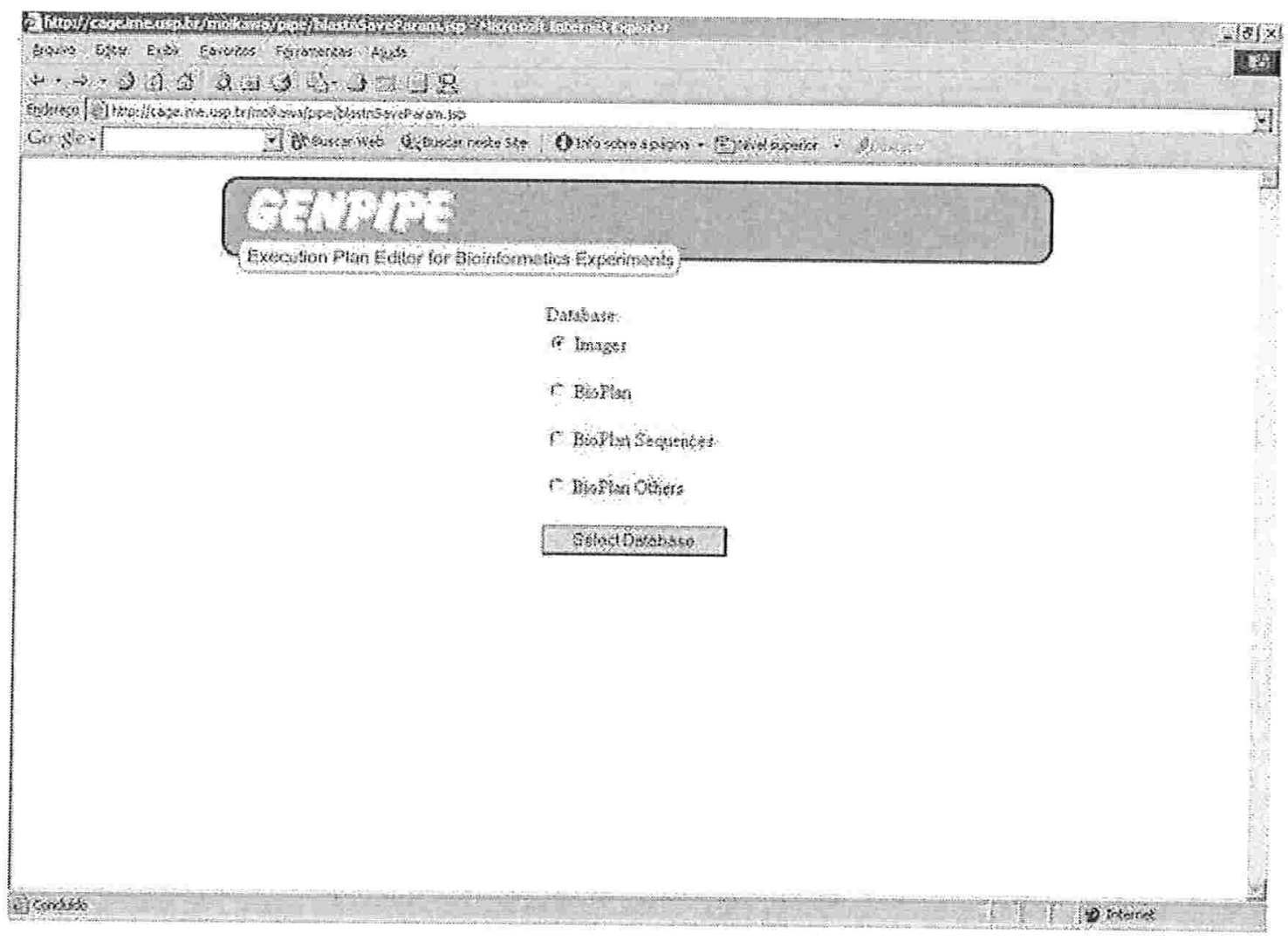

Figura 16: Integração do infopipe com bancos de dados locais e/ou remotos 


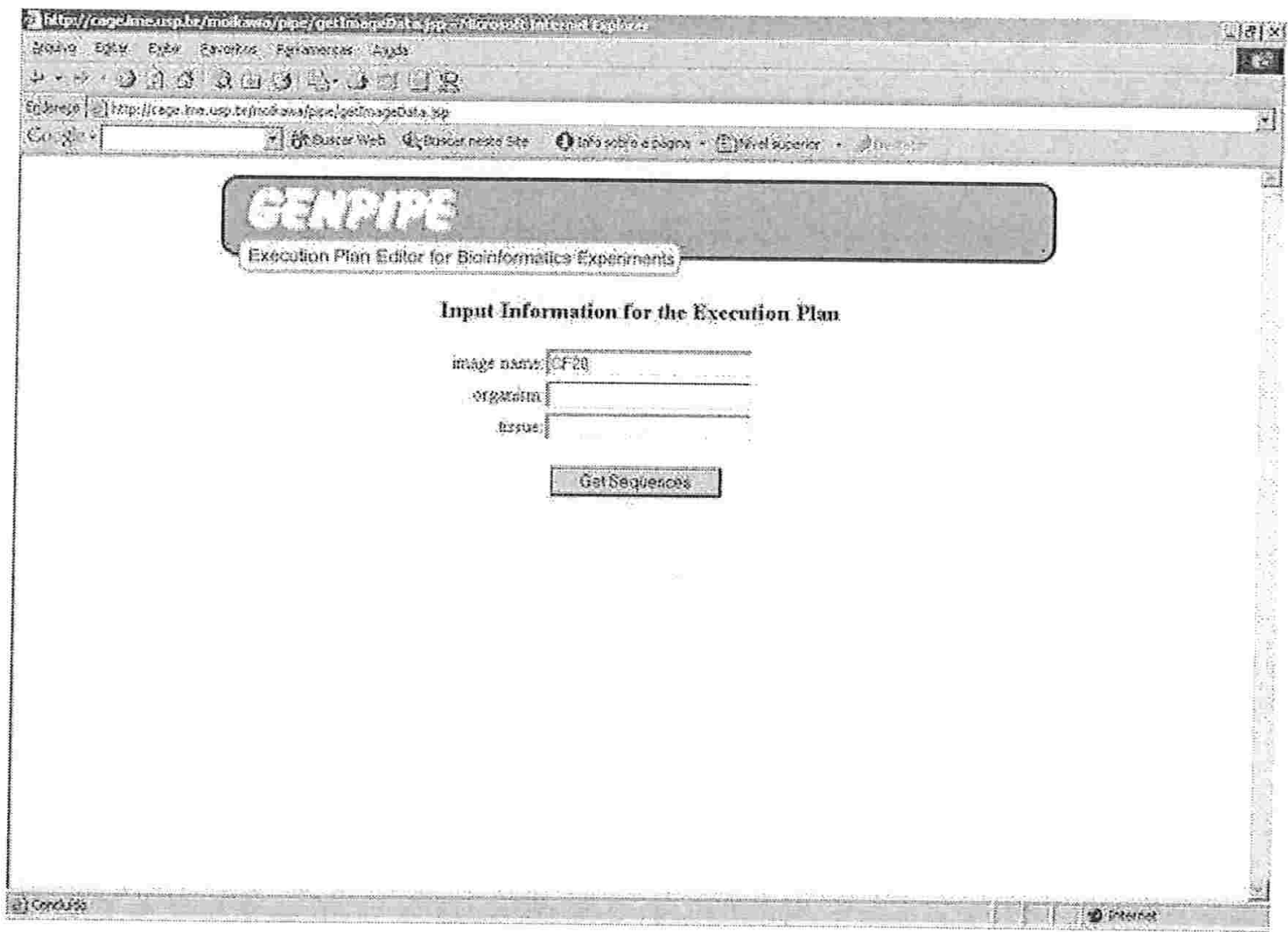

Figura 17: Tela de pesquisa de dados de entrada 


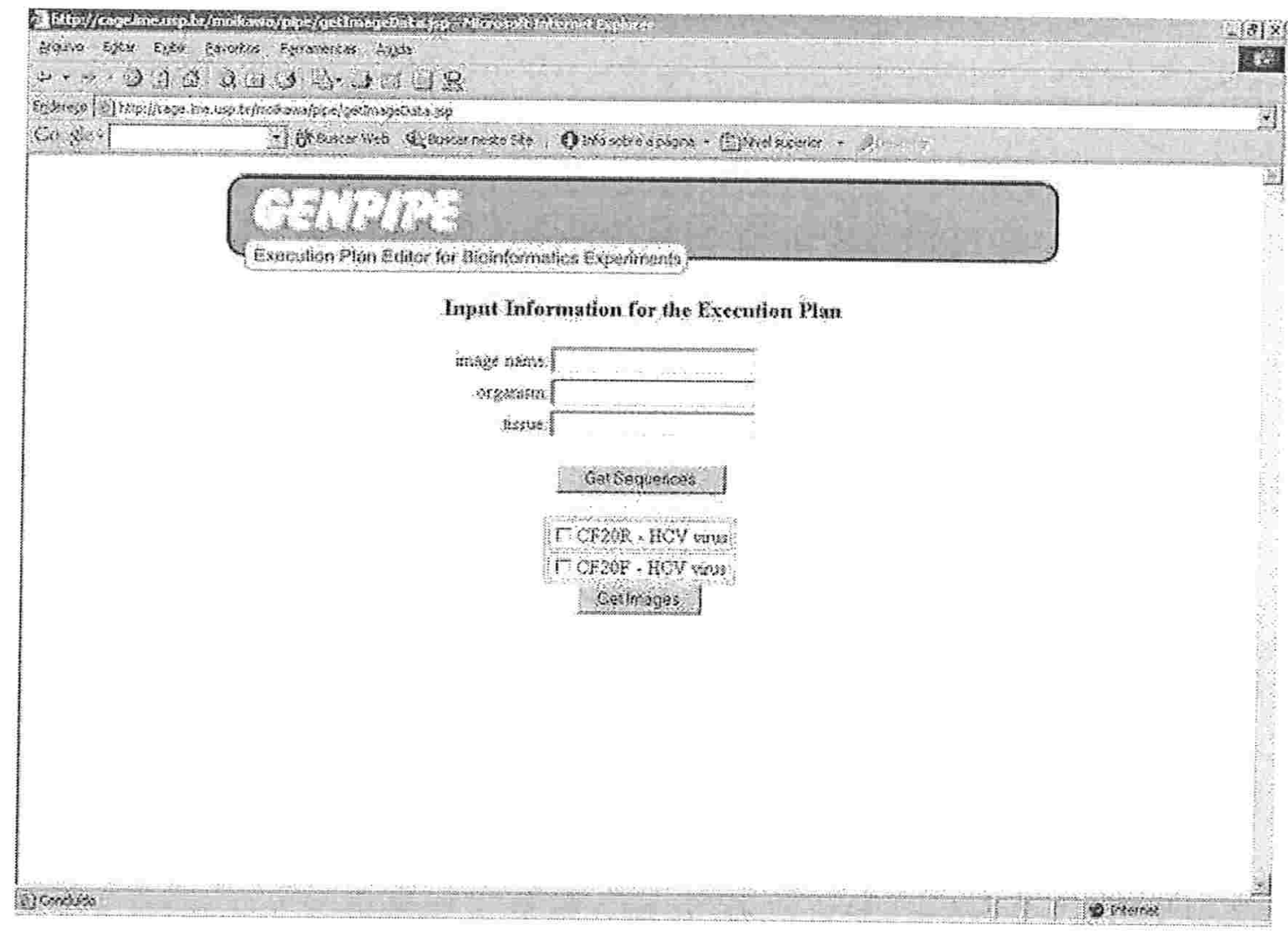

Figura 18: Tela de seleção de dados de entrada 


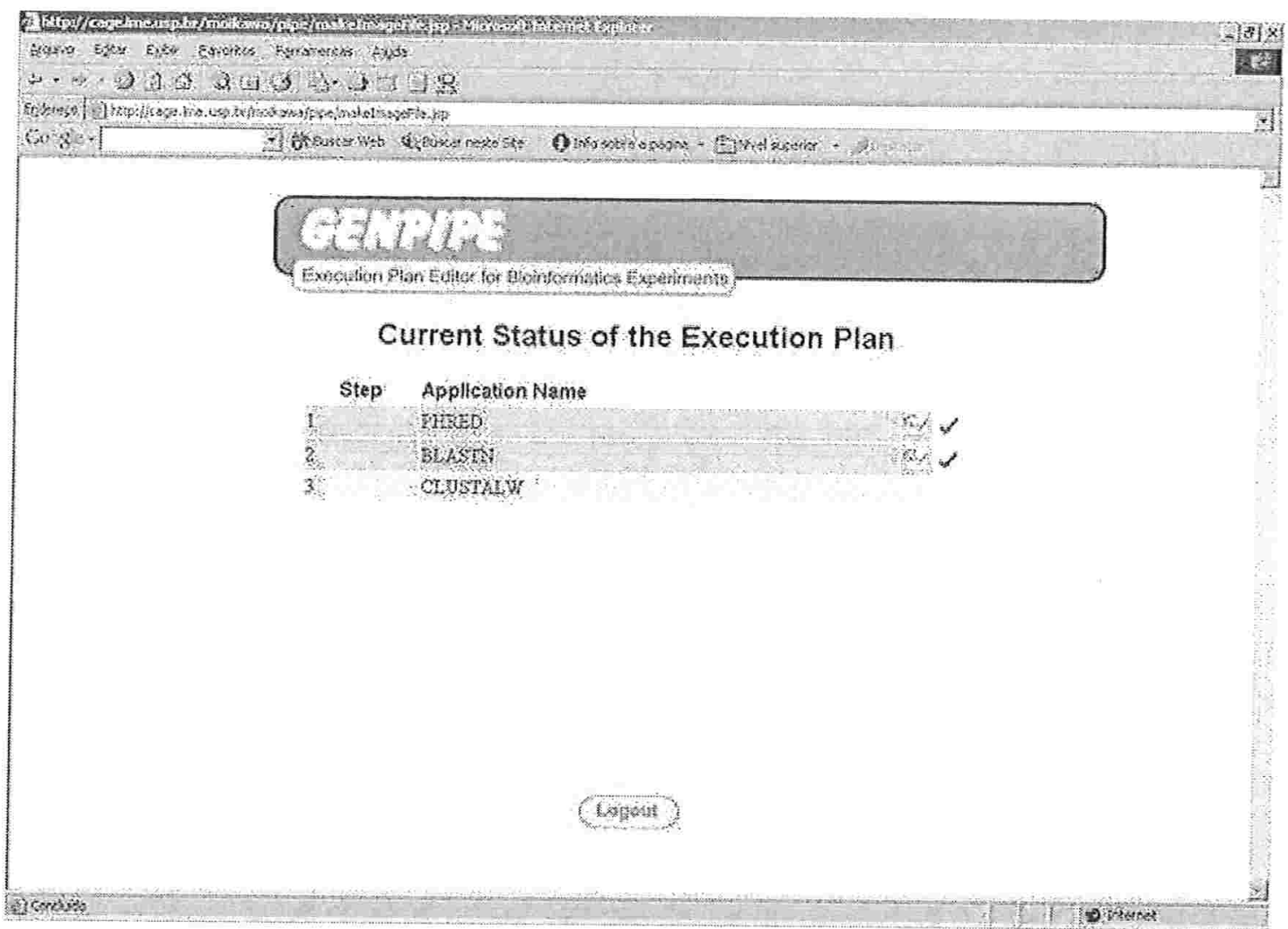

Figura 19: Acompanhamento do processo de execução 


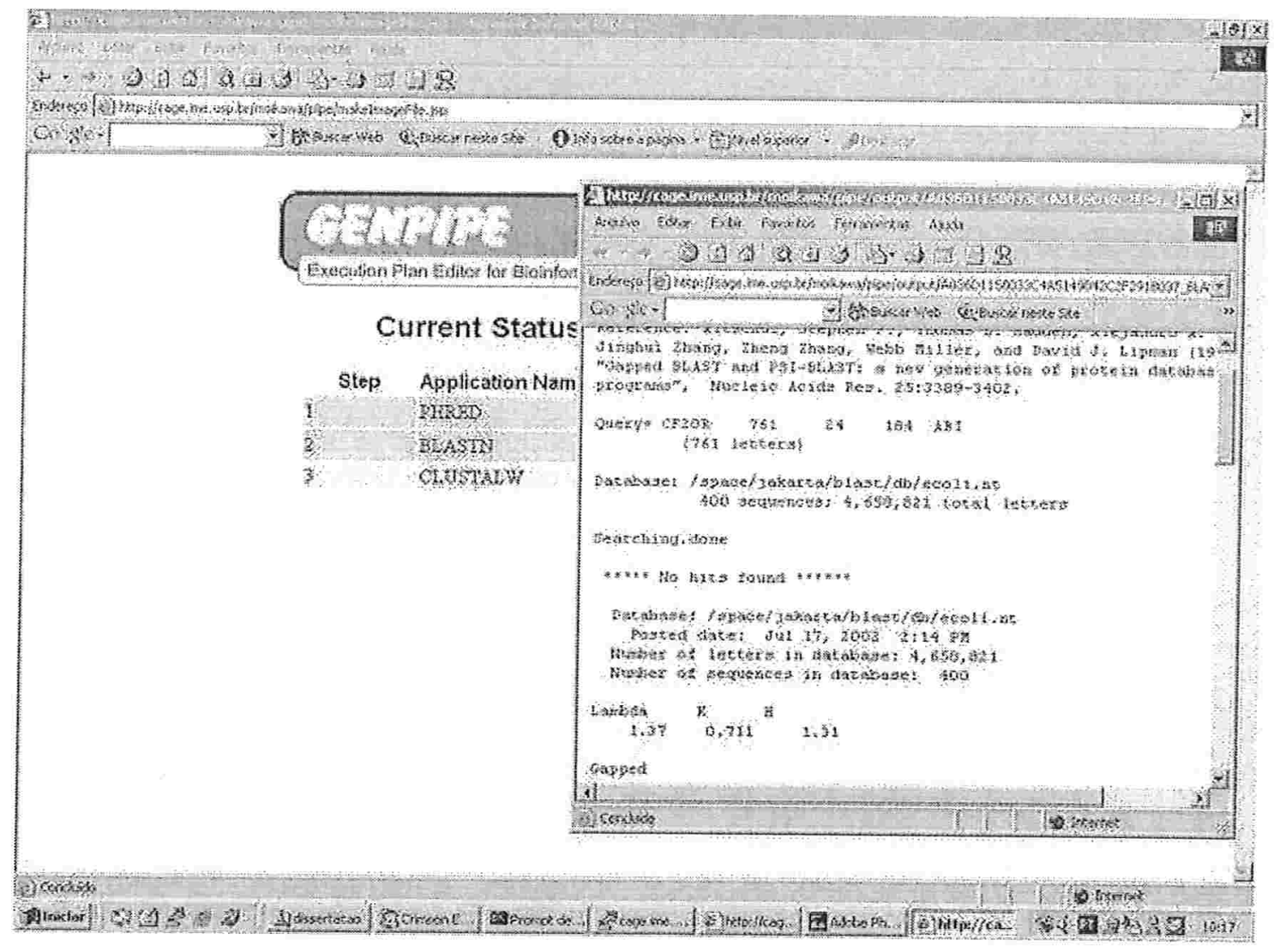

Figura 20: Acompanhamento das tarefas intermediárias do infopipe 


\section{Conclusões}

\subsection{Resultados}

Integração é uma área de constante interesse em Ciência da Computação, por seus desafios e aplicabilidade. Neste trabalho, estudamos técnicas para o tratamento de dois conceitos de heterogeneidade, que convivem de forma concomitante no ambiente de Biologia Molecular: a heterogeneidade de dados e de aplicações.

Propomos uma arquitetura de integração baseada no tratamento diferenciado de cada um destes conceitos.

Buscamos, com este trabalho, melhorar os métodos de manipulação de estruturas heterogêneas, alcançando algumas relevantes contribuições científicas, dentre as quais podemos destacar:

- Um trabalho que aborda a integração de dados e aplicações de forma simultânea, alimentando um sistema de informações;

- O estudo de técnicas alternativas para a integração de dados;

- Estudo formal das características dos dados;

- Estudo formal das características das aplicações;

- A modelagem de uma arquitetura de integração para dados e aplicações no domínio de Biologia Molecular Computacional;

- A implementação de um sistema de integração dinâmico de aplicações, com um controle genérico de fluxo de execução de tarefas (gen-pipe); 
- A implementação de um sistema de busca e recuperação de dados a partir de uma arquitetura integrada.

Procuramos destacar outros esforços nesta área, tentando aproveitar suas virtudes e deficiências. A título ilustrativo, comparamos empiricamente cada uma das contribuições atingidas por outros grupos de pesquisa com nossa abordagem. Adotamos esforços de real reconhecimento acadêmico e de grande aceitação na comunidade científica da área. Escolhemos, para avaliação, os seguintes softwares:

- GenPipe: Identificação temporária do nosso sistema de integração de dados e aplicações em Biologia Molecular Computacional.

- Artemis: Um software de visualização e anotação desenvolvido pelo Sanger Centre. Atualmente está em sua quarta versão, sendo distribuído gratuitamente, de acordo com os termos da licensa pública da GNU. Sua última versão foi compilada usando o compilador Java, versão 1.1 [62, 63];

- GCG: Pacote que agrupa uma coletânea de softwares de análise e visualização de dados da Accelrys (desde junho de 2001), [39];

- NCBI site: É um endereço web que contém um conjunto de interfaces de acesso a bancos de dados de sequências, cadeias taxonômicas, estruturas de proteínas, publicações, etc. É considerado uma referência na internet para estudos em Biologia Molecular Computacional [45]; 
- GDE: Genetic Data Environment é um software de visualização e integração de aplicações desenvolvido por um grupo de pesquisadores das universidades de Harvard, Mason, Illinois, Cambridge e Argone [38].

- Consed: Consed é um visualizador gráfico de arquivos que consegue integrar alguns softwares de análise de dados biológicos a partir de scripts de execução.

Os critérios de avaliação são listados abaixo e procuram comparar cada uma das abordagens adotada pelos grupos responsáveis de maneira genérica, considerando principalmente o nível de interatividade com o usuário. Os critério são:

- navegação: procura avaliar a dificuldade de navegação do sistema por parte do usuário. Este critério tenta avaliar o nível de simplicidade da interface do sistema. Sistemas com interface auto-explicativa e de simples interação são considerados de fácil navegação;

- instalação: indica o tipo de instalação do sistema, podendo ser classificado em "remoto" ou "local". Representa uma informação técnica do sistema, declarando o local de instalação do software;

- personalização: avalia a capacidade de personalização das operações do sistema pelo usuário. Este critério avalia a dificuldade de parametrização das operações do fluxo de execução. São consideradas ruins implementações que, quando permitem a personalização do sistema, exigem intervenção explícita do usuário em seus arquivos de configuração. À medida que as modificações nos arquivos de configuração tornam-se transparentes, este item é melhor avaliado; 
- desempenho: indica o desempenho de execução do sistema, considerando a disponibilidade dos mesmos recursos de hardware;

- escalabilidade: avalia a capacidade de escalabilidade do sistema. Consideramos um sistema escalável, neste caso, se ele permite a inclusão de novas aplicações dentro do sistema sem que isto reflita grandes alterações na implementação do sistema atualmente em funcionamento;

- integração de dados: indica se os sistemas possuem mecanismos de integração de dados. Neste caso, processos de conversão de formatos não estão sendo considerados como métodos integradores;

- integração de aplicações: avalia o nível de integração das aplicações dentro da arquitetura que foi planejada;

- interface web: indica se o sistema avaliado possui ou não uma interface internet para interação com o usuário;

- acesso: indica a política de controle de acesso de usuários adotada. Sistemas de domínio particular possuem acesso restrito, enquanto iniciativas de domínio público possuem acesso irrestrito;

- plataforma: indica se o sistema é dependente ou não de sistema operacional e, em caso positivo, qual a plataforma na qual ele está implementado: Win32, Mac, Unix ou Linux;

- interface: indica a presença ou ausência de interface gráfica no sistema. Em caso de ausência, o interação com o usuário é realizada através de linhas de comando. 
O quadro comparativo entre os critérios e os softwares analisados pode ser visto na tabela 1 a seguir.

\begin{tabular}{|c|c|c|c|c|c|c|}
\hline crit/soft & GenPipe & Artemis & GCG & NCBI site & GDE & Consed \\
\hline \hline navegação & simples & simples & difícil & difícil & média & simples \\
\hline instalação & remota & local & local/remota & remota & local & local \\
\hline personalização & boa & média & ruim & ruim & boa & muito ruim \\
\hline desempenho & bom & bom & bom & bom & bom & bom \\
\hline escalabilidade & média & média & ruim & ruim & boa & ruim \\
\hline $\begin{array}{c}\text { integração } \\
\text { de dados }\end{array}$ & sim & não & não & não & não & não \\
\hline $\begin{array}{c}\text { integração } \\
\text { de aplicações }\end{array}$ & boa & boa & boa & média & boa & média \\
interface web & sim & não & não & sim & não & não \\
\hline acesso & restrito & público & restrito & público & público & público \\
\hline plataforma & independente & independente & Unix & independente & Unix & Unix \\
\hline interface & gráfica & gráfica & comandos & gráfica & gráfica & gráfica \\
\hline
\end{tabular}

Tabela 1: Quadro comparativo de softwares de integração

Pela comparação entre alguns dos esforços existentes para a integração de dados e/ou aplicações, podemos fazer algumas avaliações:

- O GenPipe procura privilegiar usuários com familiaridade restrita com o ambiente computacional, através de um interface gráfica simples e auto-explicativa, a exemplo de outros softwares, como GDE, Artemis e e Consed. A principal diferença é que, ao contrário dos dois últimos, os dois primeiros não são apenas softwares de visualização, mas também possuem rotinas de integração entre aplicações. O NCBI possui uma interface web que também busca privilegiar a interação entre usuários e sistema, entretanto, o nível de organização do sítio internet pode levar a ciclos de interação confusos. O GCG, por outro lado, é um ambiente integrado que exige certa familiaridade com sistemas operacionais orientados a 
texto, uma vez que o nível de interatividade se restringe a linhas de comando;

- A dependência de plataforma também é um importante item de discussão. Softwares orientados a internet procuram abstrair diferenças de sistemas operacionais, implementando sistemas em várias camadas, com acesso remoto. Esta abordagem privilegia o trabalho em laboratórios com restrita capacidade de processamento computacional. Em nosso caso, GenPipe, NCBI e o Artemis compartilham este raciocínio, os dois primeiros através de implementações remotas e o último por sua implementação em Java, que também possui características multi-plataforma;

- O desempenho do sistema é semelhante para todos os casos. Esta situação ocorre porque o maior gargalo de desempenho é o próprio processamento dos dados de entrada, que tendem a ser de grande volume. Atualmente, uma das linhas de pesquisa do grupo é a otimização de recursos de hardware para execução de fluxos, conduzida por outro aluno de mestrado;

- O GenPipe é o único sistema capaz de realizar integração efetiva dos dados. Os demais sistemas possuem rotinas de tradução de formatos, entretanto o controle da integridade da informação utilizada é responsabilidade do usuário.

Além da implementação do sistema, podemos ainda apontar alguns resultados também importantes alcançados no decorrer do projeto, como:

- A construção de um protótipo de meta modelo de dados para análise de sequências de DNA. Este modelo de dados pode ser utilizado para consultas através de uma interface web, ilustrada nas figuras 7,8 e 9, diponível temporariamente no sítio internet 
http://cagedb.ime.usp.br/cage;

- A construção de um protótipo de sistema de integração de aplicações de análise de dados biológicos. Este sistema foi planejado para funcionar remotamente, através da internet, e servir como um ambiente genérico para o planejamento, parametrização e execução dos fluxos genéricos. Atualmente, este sistema está disponível em http://cagedb.ime.usp.br/moikawa/pipe, com acesso restrito para usuários cadastrados;

- Um artigo [64], publicado na XXX Reunião Anual de Bioquímica, realizada em Caxambú (Brasil), um dos mais importantes eventos da área de Química e Bioquímica no Brasil, reunindo anualmente relevantes trabalhos da área de Ciências Químicas no Brasil;

- O artigo [65], publicado na International Conference on Bioinformatics, realizada no mês de fevereiro na cidade de Bangkok (Tailândia), uma conferência na área de Bioinformática que reuniu pesquisadores e grupos de pesquisa em Biologia Molecular Computacional de diversas regiões do mundo;

- Um artigo sobre o estudo de mecanismos de integração de processos de análise de dados, através de técnicas de information flow, em fase de análise pelo comitê de programa do "3rd. IEEE Symposium on Bioinformatics and Bioengeneering".

\subsection{Trabalhos Futuros}

O trabalho também provê uma arquitetura que permite investimentos para generalização de sistemas de informação cada vez mais complexos e poderosos, aproveitando a integração dos 
dados para o desenvolvimento de algoritmos de mineração de dados, cruzamento de informação com outras fontes (por exemplo, bancos de dados clínicos e epidemiológicos), classificação, etc.

Melhorando ainda o nível de interatividade entre usuários e sistema, e abolindo a necessidade de métodos manuais de formatação de dados, este trabalho busca contribuir para a melhoria da qualidade de resultados de experimentos biológicos, otimizando a execução tarefas e abrindo a possibilidade de trabalhos mais específicos para os dados, através de cruzamentos, classificação e comparação de padrões.

Como continuidade, estamos encaminhando duas frentes de esforços: a primeira visando a implementação do núcleo de software do gen-pipe através do pedido de dois projetos de bolsas de iniciação científica submetidos à FAPESP; e a segunda, objetivando a generalização e formalização do gen-pipe para qualquer domínio de aplicação bem definido, utilizando como parte deste estudo, a realização de um projeto de doutorado. 


\section{Referências}

[1] WENGER, E. Artificial intelligence and tutoring systems: Computational and cognitive approaches to the communication of knowledge. Morgan Kauffman, 1987.

[2] FERREIRA, J. E., FINGER, M. Controle de concorrência e distribuição de dados: a teoria clássica, suas limitações e extensões modernas. 1st. ed. IME-USP, 2000.

[3] BUSICHIA, G., FERreirA, J. E. Compartilhamento de módulos de bases de dados heterogêneas através de objetos integradores. Proceedings of XIV Simposio Brasileiro de Banco de Dados, p. 395-410, 1999.

[4] BUSSE, S., KUTSCHE, R.-D., LESER, U., WEBER, H. Federated information systems: Concepts, terminology and architectures. Technical Report Forschungsberichte des Fachbereichs Informatik 99-9, 1999.

[5] BUSSE, S., KUTSCHE, R.-D., LESER, U. Strategies for the conceptual design of federated information systems. In: . c2000. p. 23-32.

[6] SHETH, A., LARSON, J. Federated database systems for managing distributed, heterogeneous, and autonomous databases. ACM Computing Surveys, v. 3, n. 22, p. 183-236, 1990 .

[7] Health level 7 standards. Disponível em http://www.hl7.org. Última visita em 31 de outubro de 2002 .

[8] ÖZSU, DAYAL, VALDURIEZ. Distributed object management. Morgan Kaufmann, 1994.

[9] TAMER, M., OZSU, VALDURIEZ, P. Principles of distributed database systems. 2nd. ed. Prentice Hall, 1999.

[10] FERREIRA, J. E., BUSICHIA, G. Database modularization design for the construction of flexible information system. Proceedings of IEEE International Database Engeneering and Application Symposium, p. 442-452, 1999.

[11] SHETH, S., GALA, S. Attribute relationships: An impediment in automating schema integration. In proceedings of NSF Workshop on Heterogeneous Databases, 1989.

[12] RAM, S., BARKMEYER, E. The unifying semantic model for accessing multiple heterogeneous databases in a manufacturing environment. In proceedings of IMSt'91 - The first International Workshop on Interoperability in Multidatabase Systems, p. 212-216, 1991.

[13] CHAWATHE, S., GARCIA-MOLINA, H., HAMMER, J., IRELAND, K., PAPAKONSTANTINOU, Y., ULLMAN, J., WIDOM, J. The tsimmis project: Integration of heterogeneous information sources. In Proceedings of IPSJ Conference, Tokyo, Japan, p. $7-18,1994$. 
[14] S. CHAWATHE, H. G.-M., WIDOM, J. Flexible constraint management for autonomous distributed databases. IEEE Data Engineering Bulletin, v. 17, n. 2, p. 23-27, 1994.

[15] HAMMER, J., GARCIA-MOLINA, H., IRELAND, K., PAPAKONSTANTINOU, Y., ULLMAN, J., WIDOM, J. Information translation, mediation, and mosaic-based browsing in the tsimmis system. In Exhibits Program of the Proceedings of the ACM SIGMOD International Conference on Management of Data, San Jose, California, p. 483, 1995.

[16] GARCIA-MOLINA, H., HAMMER, J., IRELAND, K., PAPAKONSTANTINOU, Y., ULLMAN, J., WIDOM, J. Integrating and accessing heterogeneous information sources in tsimmis. In Proceedings of the AAAI Symposium on Information Gathering, Stanford, California, p. 61-64, 1995.

[17] The tsimmis project. http://www-db.stanford.edu/tsimmis/.

[18] GARCIA-MOLINA, H., PAPAKONSTANTINOU, Y., QUASS, D., RAJARAMAN, A., SAGIV, Y., ULLMAN, J., VASSALOS, V., WIDOM, J. The tsimmis approach to mediation: Data models and languages. Journal of Intellingent Information Systems, 1997.

[19] VASSALOS, V., PAPAKONSTANTINOU, Y. Describing and using query capabilities of heterogeneous sources. In VLDB Conference, Athens, Greece, 1997.

[20] LI, C., YERNENI, R., VASSALOS, V., GARCIA-MOLINA, H., PAPAKONSTANTINOU, Y., ULLMAN, J., VALIVETI, M. Capability based mediation in tsimmis. ACM SIGMOD 98 Demo, Seattle, USA, 1998.

[21] PAPAKONSTANTINOU, Y., GARCIA-MOLINA, H., WIDOM, J. Object exchange across heterogeneous information sources. IEEE International Conference on Data Engineering, Taipei, Taiwan, p. 251-260, 1995.

[22] ULLMAN, J. D. Information integration using logic views. 6th. International Conference on Database Theory, Delphi, Greece, p. 19-40, 1997.

[23] CAlvanese, D., GIACOMO, G. D., LENZERINI, M., NARDI, D., ROSATI, R. Information integration: Conceptual modeling and reasoning support. In proceedings of 6th. Conference on Cooperative Information Systems, p. 280-291, 1998.

[24] CHIdlovskiI, B., BORGHo, U., ChEvalieR, P., CHEVAliER, Y. Toward sophisticated wrapping of web-based information repositories. In proceedings of 5th RIAO Conference, Montreal, Canada, p. 123-135, 1997.

[25] LOSCIO, B. F., SALGADO, A. C., VIDAL, V. M. P. Using agents for generation and maintenance of mediators in a data integration system on the web. Proceedings of XVI Simpósio Brasileiro de Banco de Dados, p. 172-186, 2001. 
[26] FERBER, J., GUTKNECHT, O. A meta-model for the analisys and design of organizations in multi-agents systems. Proceedings of 3rd International Conference on Multi-Agent Systems, p. 128-135, 1998.

[27] RAYMOND, D., TOMPA, F., WOOD, D. From data representation to data model: Metasemantic issues in the evolution of sgml. Computer Standards and Interfaces, v. 18, p. 25--36, 1996.

[28] MCCREADY, S. There is no more than one kind of workflow software. ComputerWorld, v. 2, november 1992 .

[29] EDER, J., GROISS, H., NEKVASIL, H. A workflow system based on active databases, 1994.

[30] EDER, J., GROISS, H., LIEBHART, W. Workflow management and databases. 2eme Forum International d Informatique Appliquee, march 1996.

[31] EDER, J., PANAGOS, E., RABINOVICH, M. Time constraints in workflow systems. Lecture Notes in Computer Science, v. 1626, p. 286-??, 1999.

[32] Object management group. http://www.omg.org/.

[33] FRATERNALI, P. Tools and approaches for developing data-intensive web applications: a survey. ACM Computing Surveys, v. 31, n. 3, p. 227-263, 1999.

[34] ZOU, Y., KONTOGIANNIS, K. Migrating and specifying services for web integration. 2000.

[35] BELLAVISTA, P., CORRADI, A., STEFANELLI, C. An integrated management environment for network resources and services. IEEE Journal on Selected Areas in Communication, v. 18 , n. 5, 2000.

[36] DAVIS, L., GAMBLE, R., PAYTON, J. The impact of component architectures on interoperability, 2002.

[37] RUTHERFORD, K., PARKHILL, J., CROOK, J., HORSNELL, T., RICE, P., RAJANDREAM, M., BARRELL, B. Artemis: sequence visualization and annotation. Bioinformatics, v. 16, p. 944-945, 2000.

[38] SMITH, S. W., OVERBEEK, R., WOESE, C. R., GILBERT, W., GILLEVET, P. M. The genetic data environment and expandable gui for multiple sequence analysis. Comput. Appl. Biosci., v. 10, n. 6, p. 671-675, 1994.

[39] Gcg wisconsin package. Disponivel em http://www.accelrys.com/about/gcg.html. Última visita em 11 de novembro de 2002.

[40] GORDON, D., ABAJIAN, C., GREEN, P. Consed: A graphical tool for sequence finishing. Genome Research, v. 8, p. 195-202, 1998. 
[41] GORDON, D., DESMARAIS, C., GREEN, P. Automated finishing with autofinish. Genome Research, v. 11, p. 614-625, 2001.

[42] EWING, B., HILLIER, L., WENDL, M., GREEN, P. Basecalling of automated sequencer traces using phred. i. accuracy assesment. Genome Research, v. 8, p. 175-185, 1998.

[43] EWING, B., GREEN, P. Basecalling of automated sequencer traces using phred. ii. error probabilities. Genome Research, v. 8, p. 186-194, 1998.

[44] ELMAGARMID, A., RUSINKIEWICZ, M., SHETH, A. Management of heterogeneous and autonomous database systems. 1st. ed. Morgan-Kaufman, 1998.

[45] National center for biotechnology information. http://www.ncbi.nlm.nih.org. 1986.

[46] European molecular biology laboratory. http://www.embl-heidelberg.de.

[47] Dna data bank of japan. http://www.ddbj.nig.ac.jp.

[48] Genbank mirror usp. http://cagedb.ime.usp.br/cage. 2000.

[49] LIU, L. A formal approach to structure, algebra and communication of complex objects, 1992. Tese de doutorado, Proefschrift Katholieke Universiteit Brabant Tilburg - the Netherlands.

[50] GAMMA, E., HELM, R., JOHNSON, R., VLISSIDES, J. Design patterns: Elements of reusable object-oriented software. Addison-Wesley, 1995.

[51] ELMASRI, R., NAVATHE, S. B. Fundamentals of database systems. 3rd. ed. AddisonWesley, 1999.

[52] SILBERSCHATZ, A., KORTH, H. F., SUDERSHAN, S. Database system concepts. 3rd. ed. McGraw-Hill, 1997.

[53] Java technology and xml. Disponível em http://java.sun.com/xml. Última visita em 28 de outubro de 2002.

[54] Extensible markup language (xml). Disponível em http://www.w3.org/XML. Última visita em 28 de outubro de 2002.

[55] ALTSCHUL, S., GISH, W., MILLER, W., MYERS, E., LIPMAN, D. Basic local alignment search tool. Journal of Molecular Biology, v. 215, p. 403-410, 1990.

[56] ALTSCHUL, S., MADDEN, T., SCHäFFER, A., ZHANG, J., ZHANG, Z., MILLER, W., LIPMAN, D. Gapped blast and psi-blast: a new generation of protein database search programs. Nucleic Acids Res., v. 25, p. 3389-3402, 1997.

[57] Phylogeny inference package. Disponivel em http://evolution.genetics.washington.edu/phylip.html. Última visita em 05 de novembro de 2002. 
[58] HIGGiNs, D., THOMPSON, J., GIBSON, T., THOMPSON, J., D.G.HIGGINS, GIBSON, $\mathrm{T}$. Clustal w: improving the sensitivity of progressive multiple sequence alignment through sequence weighting, position-specific gap penalties and weight matrix choice. Nucleic Acids Res., v. 22, p. 4673-4680, 1994.

[59] Clustalw www service at the european bioinformatics institute. Disponível em http://www.ebi.ac.uk/clustalw. Última visita em 05 de novembro de 2002.

[60] RATNER, L., ET. AL. Complete nucleotide sequence of the aids virus. Nature, London, v. 313 , n. 6000 , p. $277-284,1985$.

[61] Fasta format description. http://www.ncbi.nlm.nih.gov/BLAST/fasta.html.

[62] Artemis: a dna sequence viewer and annotation tool. Disponivel em http://www.sanger.ac.uk/Software/Artemis. Última visita em 11 de novembro de 2002.

[63] RUTHERFORD, K., PARKHILL, J., CROOK, J., HORSNELL, T., RICE, P., RAJANDREAM, M.-A., BARRELL, B. Artemis: sequence visualisation and annotation. Bioinformatics, v. 16, n. 10, p. 944-945, 2000.

[64] BAPTISTA, C., OIKAWA, M. K., FERREIRA, J. E., ZINGALES, B. Microarrays for the analysis of gene expression in strains and developmental stage of trypanossoma cruzi. Anais da XXX Reunião Anual da Sociedade Brasileira de Bioquímica e Biologia Molecular, 2001.

[65] OIKAWA, M. K., FERREIRA, J. E. Heterogeneous database integrator to support genomic data mining. In proceedings of International Conference on Bioinformatics 2002, Bangkok, Thailand, p. 88, 2002. 